See discussions, stats, and author profiles for this publication at: https://www.researchgate.net/publication/287408655

\title{
Time minimization of pocketing by zigzag passes along stability limit
}

Article in International Journal of Advanced Manufacturing Technology · December 2015

DOI: $10.1007 / 500170-015-8108-9$

CITATIONS

3 authors:

$\theta$

Chigbogu Ozoegwu

University of Nigeria

47 PUBLICATIONS 226 CITATIONS

SEE PROFILE

Engr Chinedu Anthony Ezugwu

11

9 PUBLICATIONS 38 CITATIONS

SEE PROFILE

Some of the authors of this publication are also working on these related projects:

Project Surface Engineering View project

Project Indigenized Machining Automation View project
READS

124

Sunday Ofochebe

Nnamdi Azikiwe University, Awka

10 PUBliCATIONS 92 CitATIONS

SEE PROFILE 
Chigbogu Ozoegwu, Sunday Ofochebe \& Chinedu Ezugwu, Int J Adv Manuf Technol

The final publication is available at Springer via http://dx.doi.org/[DOI 10.1007/s00170-015-8108-9]

\title{
TIME MINIMIZATION OF POCKETING BY ZIGZAG PASSES ALONG STABILITY LIMIT
}

\begin{abstract}
Pocketing with zigzag toolpath (which maintains near to continuous tool-workiece contact) that are continuously optimized with limiting pairs of axial and radial depths is investigated in this work. Analysis led to a set of sixteen conditional expressions eligible for description of pocketing time. An eligible expression becomes effective when all associated conditions are simultaneously met while the rest of the eligible expressions remain dormant until dimensions of pocket and tool favours another. Similar analysis has been carried out in other works for one-way toolpath which permits idle return passes thus expected to incur delay. Comparison of zigzag and one-way toolpaths shows that the former always hastens pocketing operation because it better utilizes the stability limit of the system by maintaining continuously optimized to and fro passes. Numerical studies gives that zigzag toolpath can even half pocketing time of one-way toolpath for some choice of limiting process parameters. Similar to conclusion that has been drawn for one-way toolpath in an earlier work it is seen that utilizing the coordinate of maximum limiting material removal rate $\left(M R R_{\text {lim }}\right)$ for both down- and up-milling in a scheme of zigzag pocketing will not necessarily provide the minimum time because of geometrical constraints.
\end{abstract}

Keywords; milling process; chatter; stability; full-discretization method; pocketing

\section{Introduction}

Regenerative chatter is a-not-yet fully resolved violent tool vibration that constrains machining productivity despite concentrated beam of research on it that spans somewhat over a century since the time of Taylor [1] who had described it as the most obscure and delicate of all problems facing the machinist. When chatter occurs there is heightened scraping of parts due to vibration marks and compromised integrity with attendant rise in economic loses. Also from ergonomic point of view chatter has to be avoided because of its noisy nature. It is inferred from the pioneering works [2-5] that described stability/instability of orthogonal turning process that regenerative chatter is self-excited and occurs as a result of unfavourable phase difference between two adjacent cuts. Shortly afterwards modelling and stability analysis of regenerative chatter of milling process were introduced by the works [6-9]. The basic milling model provided by Sridhar et al [7, 8] has the linear periodic single-discrete delayed form that still receives popular acceptance till today. The two present day popular approaches to analyzing stability of milling process are the frequency domain and time domain approaches. Frequency domain approach appeared first [10-15] probably due to its earlier application in complete analytical treatment of turning stability. The frequency domain approach is based on truncated Fourier series expansion of periodic coefficients and utilization of the Nyquist stability criterion. The Zeroth Order Approximation (ZOA) method popularized by the work [13] is the name given to the frequency domain method that utilizes only the first term in the Fourier series expansion of periodic coefficients. The ZOA method allows fast computation of practical stability diagrams but because of over-simplification, it fails to reveal other types of loss of stability that were later known to appear at low radial immersion [16-19]. Addition of higher order harmonics led to the method of Multi-Frequency Solution (MFS) which overcame the shortcomings of ZOA [20]. The frequency domain methods have been used to address the question of chatter suppression in more advanced modern-day milling models that include stabilizing effects like process damping [21], milling tools with non-uniform pitch thus having multiple discrete delays [22-24], variable helix end-mills [25, 26], serrated milling tools [27] and milling tool with spindle speed variation thus having time-varying delay [28, 29]. The semi-discretization method which basically involves discretization of the delayed term while leaving the undelayed terms undiscretized and approximating the periodic coefficient matrices as piecewise constant functions was introduced by Insperger and Stepan [30-32]. The process of semi-discretization allows the governing delay differential equation milling model to be approximated by a series of ordinary differential equations can be manipulated for stability analysis through use of the Floquet theory. The semi-discretization method is not noted for any major shortcoming even though Henninger and Eberhard [33] pointed out avenue for improved computational efficiency and accuracy. The semi-discretization method has also been used in stability analysis of more advanced milling models that include effects like process damping [34-36], tools with non-uniform pitch [37-39], variable helix end-mills [25, 38-41], spindle speed variation [42, 43], serrated milling tools [44] and tool run-out [45]. The method of temporal finite element analysis was introduced in a study of stability of interrupted cutting by Bayly et al [46]. Milling process has been variously analyzed with method of temporal finite element analysis [47-51]. The method of temporal finite element analysis is seen in reviewed literature to have been applied in stability analysis of more advanced milling models like tools with non-uniform pitch [38], variable helix end-mills [52]. The method of full-discretization was introduced [53] and reported in [54] to be closely related to the semi-discretization method except that the former is given more extended discretization that included the current state. The method is known for its marked reduction of computational time relative to the method of semi-discretization. The method of full-discretization has been applied in stability analysis of 
milling process from several perspectives: the methods based on interpolation theory [53-59], the methods based on approximation (from the least squares sense) theory [60-62] and the methods based numerical integration which is divided into that based on Newton-Coates method [63] and that based on spectral method [64]. The method of full-discretization has been applied in analysis of advance milling models like mode coupling [65], spindle speed variation [66] and curvature effects [67, 68]. Other methods that have been used in stability analysis of milling process include: Chebyshev Collocation method [69], the Lambert function based method [70], the linear approximation of acceleration based method [71] and complete discretization [72].

The milling stability limit which can be generated with any of the above listed methods is critical in planning for productive and smooth milling project. Merdol and Altintas [73] utilized the critical values of cutting force, torque, power and tool deflections in a constraint-based optimization algorithm to maximize the material removal rate (MRR) by changing the feed rate and spindle speed of an existing NC program. Their work did not consider milling stability limit but a related effort by Heo et al [74] considered it as a constraint in their formulation of objective function for high-speed pocketing time which they analyzed using the genetic algorithm. Tekeli and Budak $[75,76]$ introduced an optimization strategy that is base on stability limit on the plane of axial depth of cut and radial depth of cut instead of the traditional stability limit on the plane of spindle speed and axial depth of cut. Ozoegwu and Ezugwu [77] in further study of this optimization method identified vertical chronology (VC) as superior to horizontal chronology $(\mathrm{HC})$ in saving pocketing time and identified existence of a coordinate for optimum (maximum) limiting $\mathrm{MRR}\left(M R R_{\text {lim }}\right)$ on the curve of limiting radial immersion $\rho_{\text {lim }}$ against limiting axial depth of cut $w_{\text {lim }}$. They found that this coordinate and that of minimum pocketing time may not coincide for small pockets due to geometrical constraints but coincides if the pocket is so large that time gain from numerous passes at maximum $M R R_{\text {lim }}$ overshadows time delay due to geometric constraints. This line of research is extended in what follows to pocketing process along zigzag toolpath that maintains continuous contact between the tool and workpiece. The aim is basically to establish expressions for pocketing time as functions of stability-based prescription parameters of the system and size parameters of the tool and pocket and quantify the potential of the zigzag toolpath to save time relative to the one-way toolpath studied in [77].

\section{Mathematical model and stability analysis of milling process}

A two degree of freedom (2DOF) milling model tailored for stability analysis on the basis of the fulldiscretization method is

$$
\dot{\boldsymbol{y}}(t)=\mathbf{A} \boldsymbol{y}(t)+\mathbf{B}(t) \boldsymbol{y}(t)-\mathbf{B}(t) \boldsymbol{y}(t-\tau)
$$

where

$$
\begin{gathered}
\boldsymbol{A}=\left[\begin{array}{cccc}
0 & 1 & 0 & 0 \\
-\omega_{n x}^{2} & -2 \zeta_{x} \omega_{n x} & 0 & 0 \\
0 & 0 & 0 & 1 \\
0 & 0 & -\omega_{n y}^{2} & -2 \zeta_{y} \omega_{n y}
\end{array}\right] \\
\boldsymbol{B}(t)=\left[\begin{array}{cccc}
0 & 0 & 0 & 0 \\
-\frac{w h_{x x}(t)}{m_{x}} & 0 & -\frac{w h_{x y}(t)}{m_{x}} & 0 \\
0 & 0 & 0 & 0 \\
-\frac{w h_{y x}(t)}{m_{y}} & 0 & -\frac{w h_{y y}(t)}{m_{y}} & 0
\end{array}\right]
\end{gathered}
$$

The natural frequencies and damping ratios of the tool are given in terms of modal stiffness, mass and damping coefficient in the feed $(x)$ direction as $\omega_{n x}=\sqrt{k_{x} / m_{x}}$ and $\zeta_{x}=c_{x} / 2 \sqrt{m_{x} k_{x}}$ and in the feed-normal $(y)$ direction as $\omega_{n y}=\sqrt{k_{y} / m_{y}}$ and $\zeta_{y}=c_{y} / 2 \sqrt{m_{y} k_{y}}$. The 2DOF milling model is for regenerative vibration of end-mill under the assumption of non-compliant workpiece system. The $w$ contained in the non-zero elements of $\boldsymbol{B}(t)$ in equation (3) represents axial depth of cut. The specific force variations seen in matrix $\boldsymbol{B}(t)$ are given by

$$
\begin{aligned}
& h_{x x}(t)=C_{t} \gamma(v \tau)^{\gamma-1} \sum_{j=1}^{N} g_{j}(t) \sin ^{\gamma} \theta_{j}(t)\left[X \sin \theta_{j}(t)+\cos \theta_{j}(t)\right] \\
& h_{x y}(t)=C_{t} \gamma(v \tau)^{\gamma-1} \sum_{j=1}^{N} g_{j}(t) \sin ^{\gamma-1} \theta_{j}(t) \cos \theta_{j}(t)\left[X \sin \theta_{j}(t)+\cos \theta_{j}(t)\right]
\end{aligned}
$$




$$
\begin{aligned}
& h_{y x}(t)=C_{t} \gamma(v \tau)^{\gamma-1} \sum_{j=1}^{N} g_{j}(t) \sin ^{\gamma} \theta_{j}(t)\left[X \cos \theta_{j}(t)-\sin \theta_{j}(t)\right] \\
& h_{y y}(t)=C_{t} \gamma(v \tau)^{\gamma-1} \sum_{j=1}^{N} g_{j}(t) \sin ^{\gamma-1} \theta_{j}(t) \cos \theta_{j}(t)\left[X \cos \theta_{j}(t)-\sin \theta_{j}(t)\right]
\end{aligned}
$$

The symbols are; the tangential cutting force coefficient $C_{\mathrm{t}}$, the ratio of normal to tangential cutting force coefficient $X$, is the feed speed $v$ such that $f=v \tau$ is feed per tooth, $\tau=$ $60 /(\mathrm{N} \Omega)$ ) is the discrete delay, the spindle speed $\Omega \mathrm{rpm}$, the exponent of feed in cutting force law $\gamma$.

The angular position of $j$ th tooth $\theta_{j}(t)$ is given by

$$
\theta_{j}(t)=\left(\frac{\pi \Omega}{30}\right) t+(j-1) \frac{2 \pi}{\mathrm{N}}
$$

where $\mathrm{N}$ is the number of cutting edges of the miller. The screen function $g_{j}(t)$ has values of either unity or nullity depending on whether the tool is cutting or not. Given start and end angles of cut $\theta_{s}$ and $\theta_{e}$ respectively, $g_{j}(t)$ becomes

$$
g_{j}(t)=\left\{\begin{array}{lr}
1 \text { if } \theta_{s}<\theta_{j}(t)<\theta_{e} \\
0 \quad \text { otherwise }
\end{array}\right.
$$

The angles $\theta_{s}$ and $\theta_{e}$ are expressed in terms of radial immersion $\rho$ as

$$
\begin{aligned}
& \theta_{s}=\left\{\begin{array}{lr}
0 & \text { Up - milling } \\
\cos ^{-1}(2 \rho-1) & \text { Down - milling }
\end{array}\right. \\
& \theta_{e}=\left\{\begin{array}{cc}
\cos ^{-1}(1-2 \rho) & \text { Up - milling } \\
\pi & \text { Down - milling }
\end{array}\right.
\end{aligned}
$$

The $g_{j}(t)$ can assume the mathematical form

$$
\begin{gathered}
g_{j}(t)=\frac{1}{2}\left(1+\operatorname{sgn}\left\{\sin \left[\theta_{j}(t)-\tan ^{-1} \mathcal{P}\right]-\sin \left[\theta_{s}-\tan ^{-1} \mathcal{P}\right]\right\}\right) \\
\mathcal{P}=\frac{\sin \theta_{s}-\sin \theta_{e}}{\cos \theta_{s}-\cos \theta_{e}}
\end{gathered}
$$

The quartic full-discretization method is seen in [61] to provide the most accurate result among the methods from linear to quintic order. It is then adopted here for stability computations. The monodromy matrix is esignated $\boldsymbol{\psi}$. Analysis of eigen-values of the monodromy matrix $\boldsymbol{\psi}$ in the space of milling process parameters gives the needed stability limit. All the $4 r+4$ eigen-values or characteristic multipliers $\mu_{i}$ of $\boldsymbol{\Psi}$ must exist within the unit circle centred at the origin of the complex plane for asymptotic stability. Existence of the spectral radii on or outside the circumference of the unit circle guarantees neutral stability or instability respectively. The stability limit is the case of neutral stability that demarcates the stable space from the unstable space. The computational process of full-discretization method for arriving at the stability limit on the plane of axial depth of cut and radial depth of cut is summarized in a flow chart in appendix. On the flowchart, $r$ represents approximation parameter, $\Omega$ represents the fixed productive spindle speed, $l$ and $n$ respectively represent number of steps of computation for axial and radial depths of cut axes, $w_{1}$ and $w_{l+1}$ represent the first and last steps of axial depth respectively and $\rho_{1}$ and $\rho_{l+1}$ represent the first and last steps of radial depth respectively.

\section{Analysis of machining time}

The machining time of a pocket is dependent on prescription parameters like feed speed, axial and radial depths of cut and combined geometric restrictions of the pocket, the tool and the toolpath [77]. The prescription parameters determine the productivity of a pass while the geometric constraints determine the distribution of MRR of the tool passes needed for generating the pocket. Analysis of machining time excluding the geometric constraints of pocket and toolpath (assuming all passes are of same MRR) is simplistically given by the equation [77]

$$
t_{m}=l_{l} l_{w} l_{d} /(D w \rho v)
$$


where the rectangular pocket is of dimensions; length $l_{l}$, width $l_{w}$ and depth $l_{d}$. The symbols $D$ and $\rho$ stand for the diameter of the tool and radial immersion respectively. Analysis of machining time of this rectangular pocket considering all restrictions from optimal prescription parameters (prescription parameters selected along the stability limit), geometric restrictions and one-way toolpath has been presented in [77] for both up-milling and down-milling modes. One-way toolpath causes intermittent engagement and disengagement between the tool and workpiece (idle motion which delay the project is required at the completion of each pass to start the next pass) during pocketing operation because of the requirement to maintain a constant milling mode (either up or down milling) for all the passes in which $\rho<1$. The aim in the following analysis is to minimize pocketing time along a toolpath that always maintains optimal continuous tool-workpiece contact. The toolpath chosen to achieve this here is the zigzag toolpath as shown in figure1. The zigzag toolpath is a combination of fullyimmersed initiating passes (green arrow) and subsequent up-milling passes (red arrows) and down-milling passes (dark arrows). Vertical chronology (VC) of passes was identified in [77] to be much more time saving than Horizontal chronology (HC) of passes because VC allows preponderance of bivariate optimization in terms of axial and radial depths while $\mathrm{HC}$ allows univariate optimization in terms of either of the depths in most of its passes. For this reason only the VC is studied here for optimal pocketing along zigzag toolpath.

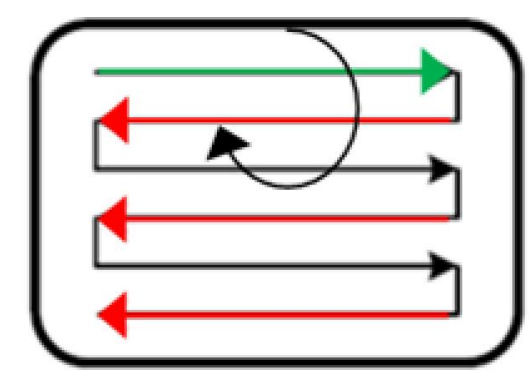

Figure1: The zigzag toolpath, the curved arrow indicates tool rotation, the green arrow indicates the fully immersed initiating pass, the red arrows indicates up-milling and the dark arrow indicates down-milling.

The VC of zigzag toolpath is illustrated in figure2 in which the red arrow indicates up-milling and the dark arrow indicates down-milling or vice versa. In the analysis that follows only vertical lifting motion of the tool after completion of a VC to start the next VC is the allowed idle motion. All the passes that align vertically with the initiating tool pass are fully-immersed thus the axial depth of cut is maximized at $\rho=1$ and designated $w_{\text {lim }}^{(\rho=1)}$ where the superscript indicates full-immersion and the subscript indicates a limiting value on the stability boundary. 


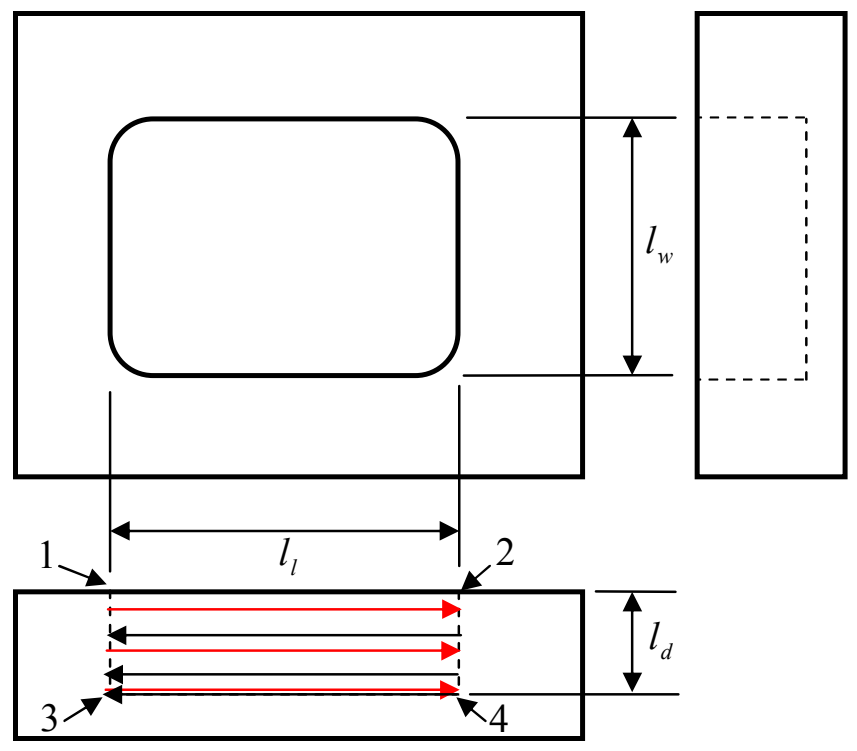

Figure2. Engineering views of rectangular pocket of length $l_{l}$, width $l_{w}$ and depth $l_{d}$ generated by zigzag toolpaths in VC. The red arrow indicates up-milling and the dark arrow indicates down-milling or vice versa.

The sum axial depth of the fully immersed to and fro passes becomes $2 w_{\text {lim }}^{(\rho=1)}$. The remnant axial depth of the first VC after the permissible whole number of to and fro axial depths is computed as

$$
w_{\text {remn }}^{(\rho=1,2 f)}=l_{d}-\text { floor }\left(\frac{l_{d}}{2 w_{\text {lim }}^{(\rho=1)}}\right) \times 2 w_{\text {lim }}^{(\rho=1)}
$$

The function floor () rounds the quotient $l_{d} /\left(2 w_{\text {lim }}^{(\rho=1)}\right)$ to the immediate lower integer while the function ceil() rounds the quotient to the immediate higher integer. The number of passes of the fully-immersed first VC becomes either

$$
N O P_{\text {even }}^{(\rho=1,2 f)}=2 \text { floor }\left(\frac{l_{d}}{2 w_{\text {lim }}^{(\rho=1)}}\right)+2 \quad \text { if } C_{1}{ }^{s t} V C=\text { floor }\left(\frac{w_{\text {remn }}^{(\rho=1,2 f)}}{w_{\text {lim }}^{(\rho=1)}}\right)=1
$$

or

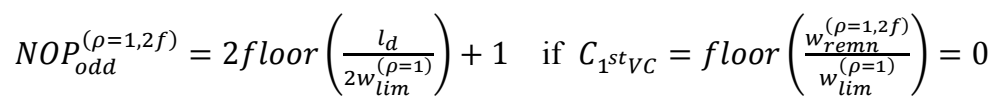

After the first set of passes of the first VC creates a boundary on one side of width of the pocket the subsequent sets of VC of passes separated by optimal step-overs will take the tool to the other side of the pocket width. Analysis of machining time of optimal pocketing zig-zag toolpath is much more complicated than that of oneway toolpath presented in [77]. This complication stems from the facts that both up- and down-milling modes are executed in completing a VC, completion of a VC that starts at point indicated 1 in figure 2 could be at either point 3 or point 4 and step-overs are not fixed. In the analysis that follows only vertical lifting motion of the tool after completion of a VC to start the next $\mathrm{VC}$ is the allowed idle motion. If a constant sense of rotation is maintained and the $\mathrm{VC}$ directly following the initiating $\mathrm{VC}$ (that is, the second VC) is completed at point 3 then execution of the rest of the VCs will be identical except the last remnant VC which will be stated at point 1 but could end at either point 3 or 4 . This situation is depicted in figure $3 a$ in which the red and blue circles represent the side of start and end of VC respectively. If the second $\mathrm{VC}$ is completed at point 4 instead then two possibilities are thrown open; (i) the third VC starts at point 2 and finishes at point 4 then execution of the rest of the VCs will be identical as depicted in figure $3 \mathrm{~b}$ except the last remnant VC which will be started at point 2 but end at either point 3 or 4 or (ii) the third VC starts at point 2 and finishes at point 3 then the following fourth 
VC will be identically executed as the second VC leading to a situation of alternating identical executions of VCs such that the even numbered VCs are executed identically and the odd numbered VCs are executed identically as depicted in figure $3 \mathrm{c}$ except possibly the last remnant VC which could start at either points 1 or 2 and end at either points 3 or 4 . In view of the above complicating possibilities the optimal pocketing time of zigzag toolpath is formulated in what follows.
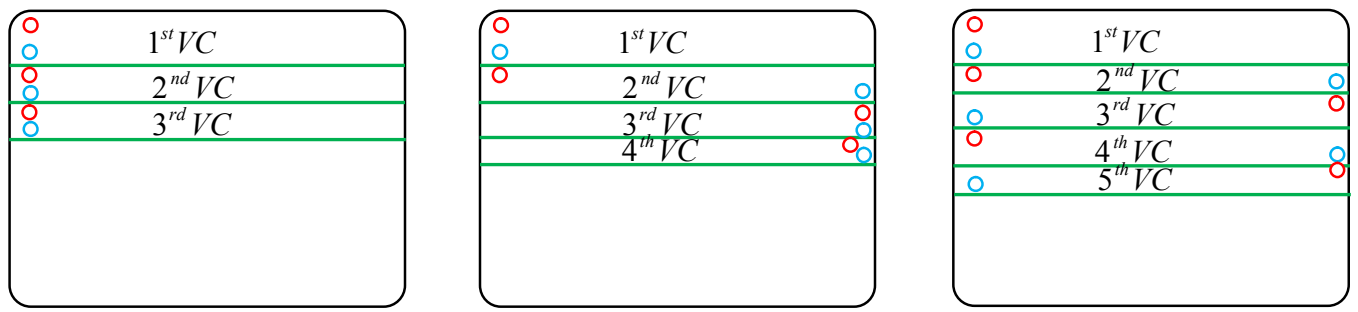

Figure3. The three patterns of executing a VCs for fixed rotational sense. The red and blue circles represent the side of start and end of $\mathrm{VC}$ respectively

The first pass of pocketing operation is prescribed without loss of generality to start at point 1 (the left side). The number of passes of the fully-immersed initiating VC is same irrespective of whether the tool rotates clockwise or counter-clockwise. After the fully-immersed initiating VC the situation that arises for execution of first pass of second $\mathrm{VC}$ is depicted in table1. It is seen in table1 that a combination of even $N O P_{\text {even }}^{(\rho=1,2 f)}$ and tool clockwise rotation gives Mode $(1,1)$ which is a down milling operation for first pass of the second VC. The other modes are interpreted same way. A thorough consideration of situations in tablel gives that after the passes of the first VC the rest of the passes needed to complete the pocket will have identical distribution of MRR for Mode (1,1) and Mode (2,2). Also identical distribution of MRR exists for Mode (1,2) and Mode (2,1). It can be more precisely stated that the 2 by 2 matrix of modes is symmetric in terms of distribution of MRR. The second row of the matrix of modes can then be ignored while analysis that follows focuses on the first row (put in red) to generate expression for pocketing time of modes $(1,1)$ and $(1,2)$. Machining time of mode $(\mathbf{1}, \mathbf{1})$ is analyzed first followed by that of mode $(1,2)$.

Table1. The conditions for execution of first pass of the second VC

\begin{tabular}{|c|c|c|}
\hline & $\begin{array}{l}N O P_{\text {even }}^{(\rho=1,2 f)} \text { and } 2^{\text {nd }} \mathrm{VC} \\
\text { starts at } 1\end{array}$ & $\begin{array}{l}N O P_{o d d}^{(\rho=1,2 f)} \text { and } 2^{\text {nd }} \mathrm{VC} \\
\text { starts at } 2\end{array}$ \\
\hline Clockwise & $\begin{array}{c}\text { Mode }(1,1) \\
\text { Down-milling }\end{array}$ & $\begin{array}{l}\text { Mode }(1,2) \\
\text { up-milling }\end{array}$ \\
\hline Counter-clockwise & $\begin{array}{l}\text { Mode }(2,1) \\
\text { up-milling }\end{array}$ & $\begin{array}{c}\text { Mode }(2,2) \\
\text { Down-milling }\end{array}$ \\
\hline
\end{tabular}

\subsection{Machining time of mode $(1,1)$}

A pair of limiting axial and radial depths of cut at a productive spindle speed designated respectively as $w_{\text {lim }}^{\left(\rho_{\text {lim }}^{(d)}, d\right)}$ and $\rho_{\text {lim }}^{(d)}$ is chosen for the first down-milling pass (the to pass) of the second VC. The return upmilling pass (the fro pass) is then carried out at $w_{\text {lim }}^{\left(\rho_{\text {lim }}^{(d)}, u\right)}$ and $\rho_{\text {lim }}^{(d)}$. It must be noted that the radial immersion of the to pass is retained in the fro pass while the axial depth of cut $w_{\text {lim }}^{\left(\rho_{\text {lim }}^{(d)}, u\right)}$ is read from up-milling stability diagram. The superscript system is such that for example the " $d$ " on $\rho_{\text {lim }}^{(d)}$ connotes the mode of operation of stability diagram from which $\rho_{\text {lim }}^{(d)}$ is read off while the second " $u$ " connotes the mode of operation of stability diagram from which $w_{\text {lim }}^{\left(\rho_{\text {lim }}^{(d)}, u\right)}$ is read off while retaining the radial immersion at $\rho_{\text {lim }}^{(d)}$. 
Chigbogu Ozoegwu, Sunday Ofochebe \& Chinedu Ezugwu, Int J Adv Manuf Technol The final publication is available at Springer via http://dx.doi.org/[DOI 10.1007/s00170-015-8108-9]

(a)

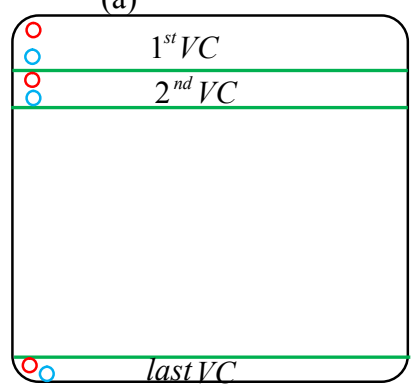

(d)

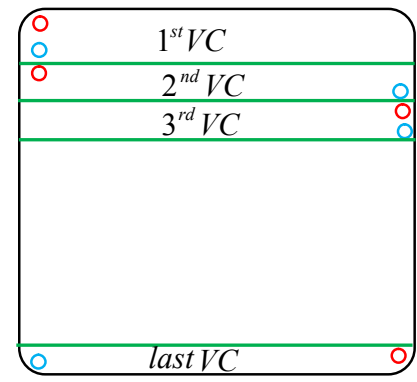

(g)

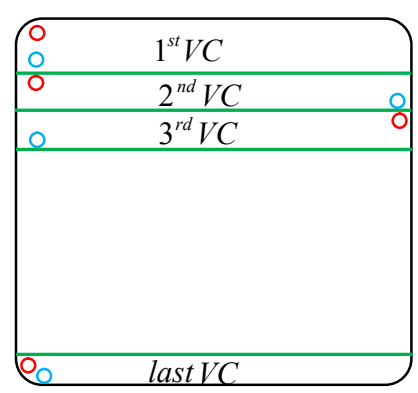

(b)

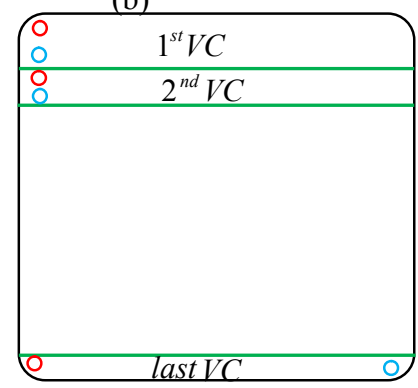

(e)

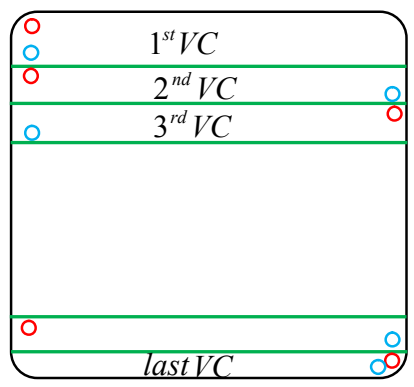

(h)

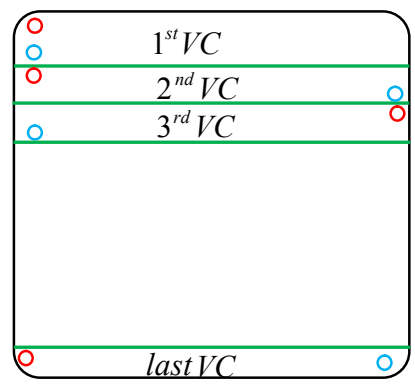

(c)

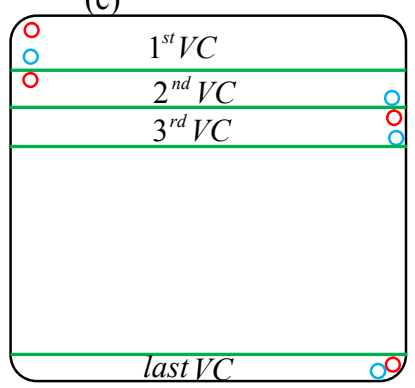

(f)

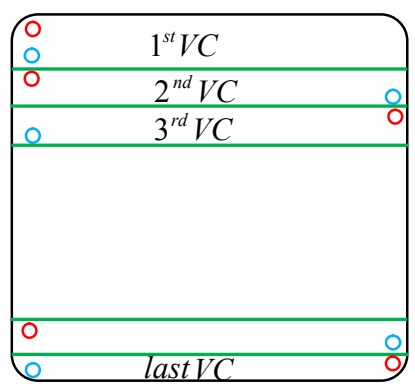

Figure4. the conditions for machining times of mode $(1,1)$ (a) equations $(20 \mathrm{a}, 25 \mathrm{a}, 26 \mathrm{a})$, (b) equations $(20 \mathrm{a}$, 25b, 26b), (c) equations (20b, 29a, 34a, 35a), (d) equations (20b, 29a, 34b, 35b), (e) equations (20b, 29b, 37, 41a, 42a), (f) equations (20b, 29b, 37, 41b, 42b), (g) equations (20b, 29b, 43, 47a, 48a), (h) equations (20b, 29b, $43,47 b, 48 b)$

The sum axial depth of the to and fro passes become

$$
w_{\text {lim }}^{\left(\rho_{\text {lim }}^{(d)}, d+u\right)}=w_{\text {lim }}^{\left(\rho_{\text {lim }}^{(d)}, d\right)}+w_{\text {lim }}^{\left(\rho_{\text {lim }}^{(d)}, u\right)}
$$

The remnant axial depth of the second VC after the permissible whole number of to and fro axial depths is computed as

$$
w_{\text {remn }}^{\left(\rho_{\text {lim }}^{(d)}, d+u\right)}=l_{d}-\text { floor }\left(\frac{l_{d}}{w_{\text {lim }}^{\left(\rho_{\text {lim }}^{(d)}, d+u\right)}}\right) \times w_{\text {lim }}^{\left(\rho_{\text {lim }}^{(d)}, d+u\right)}
$$

The number of passes of the bivariately optimized second VC becomes 
Chigbogu Ozoegwu, Sunday Ofochebe \& Chinedu Ezugwu, Int J Adv Manuf Technol The final publication is available at Springer via http://dx.doi.org/[DOI 10.1007/s00170-015-8108-9]

$$
N O P_{\text {even }}^{\left(\rho_{\text {lim }}^{(d)}, d+u\right)}=2 \text { floor }\left(\frac{l_{d}}{w_{\text {lim }}^{\left(\rho_{\text {lim }}^{(d)}, d+u\right)}}\right)+2 \quad \text { if } C_{2} n d_{V C}=f l o o r\left(\frac{w_{\text {remn }}^{\left(\rho_{\text {lim }}^{(d)}, d+u\right)}}{w_{\text {lim }}^{\left(\rho_{\text {lim }}^{(d)}, d\right)}}\right)=1
$$

or

$$
N O P_{o d d}^{\left(\rho_{\text {lim }}^{(d)}, d+u\right)}=2 f \operatorname{loor}\left(\frac{l_{d}}{w_{\text {lim }}^{\left(\rho_{\text {lim }}^{(d)}, d+u\right)}}\right)+1 \quad \text { if } C_{2^{n d} d_{V C}}=f l o o r\left(\frac{w_{r e m n}^{\left(\rho_{\text {lim }}^{(d)}, d+u\right)}}{w_{\text {lim }}^{\left(\rho_{\text {lim }}^{(d)}, d\right)}}\right)=0
$$

Suppose equation (20a) holds, the number of bivariately optimized VCs for which $\rho_{\text {lim }}^{(d)}$ becomes

$$
N O P_{\text {even,total }(M 1,1)}^{\left(\rho_{\text {lim }}^{(d)}, d+u\right)}=f \operatorname{floor}\left(\frac{l_{w}-D}{\rho_{\text {lim }}^{(d)} D}\right) N O P_{\text {even }}^{\left(\rho_{\text {lim }}^{(d)}, d+u\right)}=f l o o r\left(\frac{l_{w}}{\rho_{\text {lim }}^{(d)} D}-\frac{1}{\rho_{\text {lim }}^{(d)}}\right) N O P_{\text {even }}^{\left(\rho_{\text {lim }}^{(d)}, d+u\right)}
$$

The radial immersion for the last $\mathrm{VC}$ that also starts at point 1 is given by

$$
\rho_{\text {remn }(M 1,1)}^{(d)}=\frac{l_{w}}{D}-1-\text { floor }\left(\frac{l_{w}-D}{\rho_{\text {lim } D}^{(d)}}\right) \rho_{\text {lim }}^{(d)}
$$

Axial depths $w_{\text {lim }}^{\left(\rho_{\text {remn }(M 1,1)}^{(d)}, d\right)}$ and $w_{\text {lim }}^{\left(\rho_{\text {remn }(M 1,1)}^{(d)}, u\right)}$ are read from the stability diagram of down-milling and upmilling respectively at fixed radial immersion $\rho_{\text {remn }}^{(d)}$. The sum axial depth of the to and fro passes of the last VC becomes

$$
w_{\text {lim }}^{\left(\rho_{\text {remn }(M 1,1)}^{(d)}, d+u\right)}=w_{\text {lim }}^{\left(\rho_{\text {remn }(M 1,1)}^{(d)}, d\right)}+w_{\text {lim }}^{\left(\rho_{\text {remn }(M 1,1)}^{(d)}, u\right)}
$$

The remnant axial depth of the last $\mathrm{VC}$ after the permissible whole number of to and fro axial depths is computed as

$$
w_{\text {remn }}^{\left(\rho_{\text {remn }(M 1,1)}^{(d)}, d+u\right)}=l_{d}-\text { floor }\left(\frac{l_{d}}{w_{\text {lim }}^{\left(\rho_{\text {remn }(M 1,1)}^{(d)}, d+u\right)}}\right) \times w_{\text {lim }}^{\left(\rho_{\text {remn }(M 1,1)}^{(d)}, d+u\right)}
$$

The number of passes of the last $\mathrm{VC}$ becomes either

$$
N O P_{\text {even }}^{\left(\rho_{\text {remn }(M 1,1)}^{(d)}, d+u\right)}=2 \text { floor }\left(\frac{l_{d}}{w_{\text {lim }}^{\left(\rho_{\text {remn }(M 1,1)}^{(d)}, d+u\right)}}\right)+2 \quad \text { if } C_{\text {last VC }}=f \operatorname{loor}\left(\frac{w_{\text {remn }}^{\left(\rho_{\text {remn }(M 1,1)}^{(d)}, d+u\right)}}{w_{\text {lim }}^{\left(\rho_{\text {remn }(M 1,1)}^{(d)}, d\right)}}\right)=1
$$

such that the machining time becomes

$$
t_{m}=\frac{l_{l}-D}{v}\left[N O P_{\text {even }}^{(\rho=1,2 f)}+N O P_{\text {even, total }(M 1,1)}^{\left(\rho_{\text {lim }}^{(d)}, d+u\right)}+N O P_{\text {even }}^{\left(\rho_{\text {remn }(M 1,1)}^{(d)}, d+u\right)}\right]
$$

or

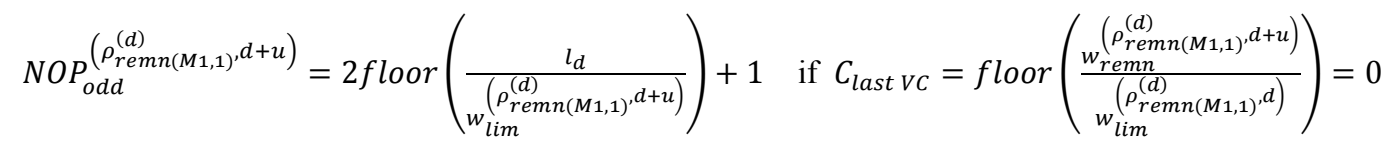

such that the machining time then becomes

$$
t_{m}=\frac{l_{l}-D}{v}\left[N O P_{\text {even }}^{(\rho=1,2 f)}+N O P_{\text {even, total }(M 1,1)}^{\left(\rho_{\text {lim }}^{(d)}, d+u\right)}+N O P_{\text {odd }}^{\left(\rho_{\text {remn }(M 1,1)}^{(d)}, d+u\right)}\right]
$$


Chigbogu Ozoegwu, Sunday Ofochebe \& Chinedu Ezugwu, Int J Adv Manuf Technol The final publication is available at Springer via http://dx.doi.org/[DOI 10.1007/s00170-015-8108-9]

For the case where equation (20b) holds the first pass of the third VC is in up-milling mode. A pair of limiting axial and radial depths of cut designated respectively as $w_{\text {lim }}^{\left(\rho_{\text {lim }}^{(u)}, u\right)}$ and $\rho_{\text {lim }}^{(u)}$ is chosen for the first up-milling pass (the to pass) of the third VC. The return down-milling pass (the fro pass) is then carried out at $w_{\text {lim }}^{\left(\rho_{\text {lim }}^{(u)}, d\right)}$ and $\rho_{\text {lim }}^{(u)}$. It must be noted that the radial immersion of the to pass is retained in the fro pass while the axial depth of cut $w_{\text {lim }}^{\left(\rho_{\text {lim }}^{(u)}, d\right)}$ is read from down-milling stability diagram. The sum axial depth of the to and fro passes becomes

$$
w_{\text {lim }}^{\left(\rho_{\text {lim }}^{(u)}, u+d\right)}=w_{\text {lim }}^{\left(\rho_{\text {lim }}^{(u)}, u\right)}+w_{\text {lim }}^{\left(\rho_{\text {lim }}^{(u)}, d\right)}
$$

The remnant axial depth of the third VC after the permissible whole number of to and fro axial depths is computed as

$$
w_{\text {remn }}^{\left(\rho_{\text {lim }}^{(u)}, u+d\right)}=l_{d}-\text { floor }\left(\frac{l_{d}}{w_{\text {lim }}^{\left(\rho_{\text {lim }}^{(u)}, u+d\right)}}\right) \times w_{\text {lim }}^{\left(\rho_{\text {lim }}^{(u)}, u+d\right)}
$$

The number of passes of the bivariately optimized third $\mathrm{VC}$ becomes

$$
N O P_{\text {even }}^{\left(\rho_{\text {lim }}^{(u)}, u+d\right)}=2 \text { floor }\left(\frac{l_{d}}{w_{\text {lim }}^{\left(\rho_{\text {lim }}^{(u)}, u+d\right)}}\right)+2 \quad \text { if } C_{3^{r d}}=f\left(\operatorname{loor}\left(\frac{w_{\text {remn }}^{\left(\rho_{\text {lim }}^{(u)}, u+d\right)}}{w_{\text {lim }}^{\left(\rho_{\text {lim }}^{(u)}, u\right)}}\right)=1\right.
$$

or

$$
N O P_{o d d}^{\left(\rho_{\text {lim }}^{(u)}, u+d\right)}=2 \text { floor }\left(\frac{l_{d}}{w_{\text {lim }}^{\left(\rho_{\text {lim }}^{(u)}, u+d\right)}}\right)+1 \quad \text { if } C_{3} \text { rd }{ }_{V C}=\text { floor }\left(\frac{w_{\text {remn }}^{\left(\rho_{\text {lim }}^{(u)}, u+d\right)}}{w_{\text {lim }}^{\left(\rho_{\text {lim }}^{(u)}, u\right)}}\right)=0
$$

Suppose equation (29a) holds, the number of bivariately optimized VCs for which $\rho_{\text {lim }}^{(u)}$ becomes

$$
N O P_{\text {even,total }(M 1,1)}^{\left(\rho_{\text {lim }}^{(u)}, u+d\right)}=f \operatorname{floor}\left(\frac{l_{w}-D-\rho_{\text {lim }}^{(d)} D}{\rho_{\text {lim }}^{(u)} D}\right) N O P_{\text {even }}^{\left(\rho_{\text {lim }}^{(u)}, u+d\right)}
$$

The radial immersion for the last $\mathrm{VC}$ that also starts at point 2 is given by

$$
\rho_{\text {remn }(M 1,1)}^{(u)}=\frac{l_{w}}{D}-1-\rho_{\text {lim }}^{(d)}-\text { floor }\left(\frac{l_{w}-D-\rho_{\text {lim }}^{(d)} D}{\rho_{\text {lim }}^{(u)} D}\right) \rho_{\text {lim }}^{(u)}
$$

Axial depths $w_{\text {lim }}^{\left(\rho_{\text {remn(M1,1) }}^{(u)}, u\right)}$ and $w_{\text {lim }}^{\left(\rho_{\text {remn(M1,1) }}^{(u)}, d\right)}$ are read from the stability diagram of up-milling and downmilling respectively at fixed radial immersion $\rho_{\text {remn }(M 1,1)}^{(u)}$. The sum axial depth of the to and fro passes of the remnant VC becomes

$$
w_{\text {lim }}^{\left(\rho_{\text {remn }(M 1,1)}^{(u)}, u+d\right)}=w_{\text {lim }}^{\left(\rho_{\text {remn }(M 1,1)}^{(u)}, u\right)}+w_{\text {lim }}^{\left(\rho_{\text {remn }(M 1,1)}^{(u)}, d\right)}
$$

The remnant axial depth of the last $\mathrm{VC}$ after the permissible whole number of to and fro axial depths is computed as

$$
w_{\text {remn }}^{\left(\rho_{\text {remn }(M 1,1)}^{(u)}, u+d\right)}=l_{d}-\text { floor }\left(\frac{l_{d}}{w_{\text {lim }}^{\left(\rho_{\text {remn }(M 1,1)}^{(u)}, u+d\right)}}\right) \times w_{\text {lim }}^{\left(\rho_{\text {remn }(M 1,1)}^{(u)}, u+d\right)}
$$

The number of passes of the last $\mathrm{VC}$ becomes either 
Chigbogu Ozoegwu, Sunday Ofochebe \& Chinedu Ezugwu, Int J Adv Manuf Technol The final publication is available at Springer via http://dx.doi.org/[DOI 10.1007/s00170-015-8108-9]

$$
N O P_{\text {even }}^{\left(\rho_{\text {remn }(M 1,1)}^{(u)}, u+d\right)}=2 \text { floor }\left(\frac{l_{d}}{w_{\text {lim }}^{\left(\rho_{\text {remn }(M 1,1)}^{(u)}, u+d\right)}}\right)+2 \quad \text { if } C_{\text {last } V C}=f \operatorname{floor}\left(\frac{w_{\text {remn }}^{\left(\rho_{\text {remn }(M 1,1)}^{(u)}, u+d\right)}}{w_{\text {lim }}^{(u)}\left(\rho_{\text {remn }(M 1,1)}^{, u}\right)}\right)=1
$$

such that the machining time becomes

$$
t_{m}=\frac{l_{l}-D}{v}\left[N O P_{\text {even }}^{(\rho=1,2 f)}+N O P_{\text {odd }}^{\left(\rho_{\text {lim }}^{(d)}, d+u\right)}+N O P_{\text {even,total }(M 1,1)}^{\left(\rho_{\text {lim }}^{(u)}, u+d\right)}+N O P_{\text {even }}^{\left(\rho_{\text {remn }(M 1,1)}^{(u)}, u+d\right)}\right]
$$

or The number of passes of the remnant VC becomes either

$$
N O P_{o d d}^{\left(\rho_{\text {remn }(M 1,1)}^{(u)}, u+d\right)}=2 f \operatorname{floor}\left(\frac{l_{d}}{w_{\text {lim }}^{\left(\rho_{\text {remn }(M 1,1)}^{(u)}, u+d\right)}}\right)+1 \quad \text { if } C_{\text {last } V C}=f \operatorname{floor}\left(\frac{w_{\text {remn }}^{\left(\rho_{\text {remn }(M 1,1)}^{(u)}, u+d\right)}}{w_{\text {lim }}^{\left(\rho_{\text {remn }(M 1,1)}^{(u)}, u\right)}}\right)=0
$$

such that the machining time becomes

$$
t_{m}=\frac{l_{l}-D}{v}\left[N O P_{\text {even }}^{(\rho=1,2 f)}+N O P_{\text {odd }}^{\left(\rho_{\text {lim }}^{(d)}, d+u\right)}+N O P_{\text {even,total }(M 1,1)}^{\left(\rho_{\text {lim }}^{(u)}, u+d\right)}+N O P_{\text {odd }}^{\left(\rho_{\text {remn }(M 1,1)}^{(u)}, u+d\right)}\right]
$$

If equation (29b) holds instead then $N O P_{o d d}^{\left(\rho_{\text {lim }}^{(d)}, d+u\right)}$ as given in equation $(20 \mathrm{~b})$ and $N O P_{o d d}^{\left(\rho_{\text {lim }}^{(u)}, u+d\right)}$ as given in equation (29b) will alternate. The alternation starts from the second VC. Under this condition the radial immersion remaining after the bivariately optimized VCs is given as

$$
\rho_{\text {remn }}^{(a l t, d+u)}=\frac{l_{w}}{D}-1-\text { floor }\left(\frac{l_{w}-D}{\left(\rho_{\text {lim }}^{(d)}+\rho_{\text {lim }}^{(u)}\right) D}\right)\left(\rho_{\text {lim }}^{(d)}+\rho_{\text {lim }}^{(u)}\right)
$$

The total number of passes of bivariately optimized VCs becomes

$$
\begin{aligned}
& N O P_{\text {alt1,total }(M 1,1)}^{(d+u)} \\
& =\left[N O P_{o d d}^{\left(\rho_{\text {lim }}^{(d)}, d+u\right)}+N O P_{o d d}^{\left(\rho_{\text {lim }}^{(u)}, u+d\right)}\right] \text { floor }\left(\frac{l_{w}-D}{\left(\rho_{\text {lim }}^{(d)}+\rho_{\text {lim }}^{(u)}\right) D}\right) \\
& +N O P_{o d d}^{\left(\rho_{\text {lim }}^{(d)}, d+u\right)} \quad \text { if } C_{00, \text { last1or2VCs }}=\text { floor }\left(\frac{\rho_{\text {remn }}^{(\text {alt }, d+u)}}{\rho_{\text {lim }}^{(d)}}\right)=1
\end{aligned}
$$

The two zeros in the subscript of $C_{00, \text { last1or2VCs }}$ represents that the condition originates from number of passes of both the second and third VC being odd and "last1or2VCs" represents that the condition is centred on the last or last-but-one VC. Radial immersion of the last VC becomes

$$
\rho_{\text {remn }(M 1,1)}^{(a l t, u)}=\rho_{\text {remn }}^{(a l t, d+u)}-\rho_{\text {lim }}^{(d)}
$$

The $w_{\text {lim }}^{\left(\rho_{\text {remn(M1,1) }}^{(a l t, u)}, u\right)}$ and $w_{\text {lim }}^{\left(\rho_{\text {remn(M1,1) }}^{(a l t, u)}, d\right)}$ are read at $\rho_{\text {remn }(M 1,1)}^{(a l t, u)}$ from the up-milling and down-milling stability diagrams respectively. The sum axial depth of the to and fro passes of the last VC becomes

$$
w_{\text {lim }}^{\left(\rho_{\text {remn }(M 1,1)}^{(\text {alt }, u+d)}\right.}=w_{\text {lim }}^{\left(\rho_{\text {remn }(M 1,1)}^{(\text {alt }, u)}, u\right)}+w_{\text {lim }}^{\left(\rho_{\text {remn(M1,1) }}^{(\text {alt }, u)}, d\right)}
$$

The remnant axial depth of the last VC is computed as

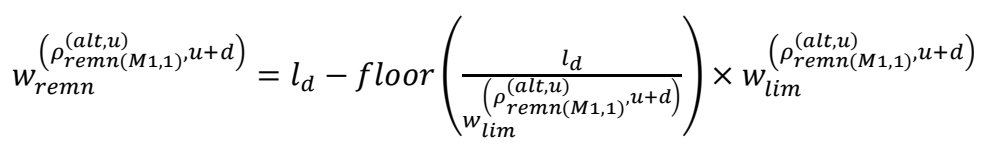

The number of passes of the last VC becomes either 
Chigbogu Ozoegwu, Sunday Ofochebe \& Chinedu Ezugwu, Int J Adv Manuf Technol The final publication is available at Springer via http://dx.doi.org/[DOI 10.1007/s00170-015-8108-9]

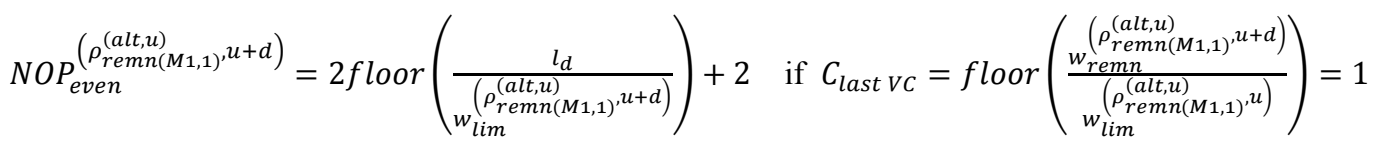

Such that machining time becomes

$$
t_{m}=\frac{l_{l}-D}{v}\left[N O P_{\text {even }}^{(\rho=1,2 f)}+N O P_{\text {alt } 1, \operatorname{total}(M 1,1)}^{(d+u)}+N O P_{\text {even }}^{\left(\rho_{\text {remn }(M 1,1)}^{(a l t, u)}, u+d\right)}\right]
$$

or

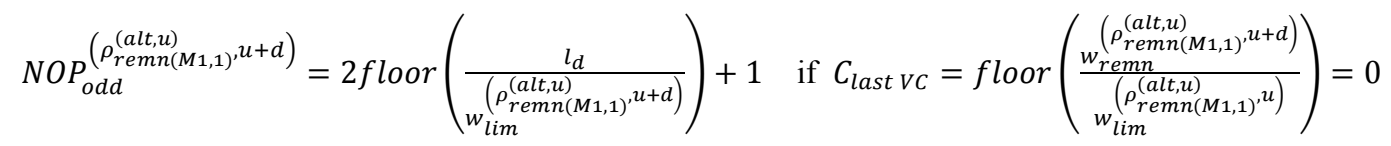

Such that machining time becomes

$$
t_{m}=\frac{l_{l}-D}{v}\left[N O P_{\text {even }}^{(\rho=1,2 f)}+N O P_{\text {alt1,total }(M 1,1)}^{(d+u)}+N O P_{\text {odd }}^{\left(\rho_{\text {remn( }(M 1,1)}^{(a l), u+d)}\right)}\right]
$$

Instead of equation (37) the other equation that can hold for the total number of passes of bivariately optimized alternating VCs is

$$
\begin{aligned}
N O P_{\text {alt } 2, \text { total }(M 1,1)}^{(d+u)} & =\left[N O P_{o d d}^{\left(\rho_{\text {lim }}^{(d)}, d+u\right)}+N O P_{o d d}^{\left(\rho_{\text {lim }}^{(u)}, u+d\right)}\right] \text { floor }\left(\frac{l_{w}-D}{\left(\rho_{\text {lim }}^{(d)}+\rho_{\text {lim }}^{(u)}\right) D}\right) \quad \text { if } C_{00, \text { last1or2VCs }} \\
& =\text { floor }\left(\frac{\rho_{\text {remn }(M 1,1)}^{(a l t, d+u)}}{\rho_{\text {lim }}^{(d)}}\right)=0
\end{aligned}
$$

Radial immersion of the last VC becomes

$$
\rho_{\text {remn }(M 1,1)}^{(a l t, d)}=\rho_{\text {remn }}^{(a l t, d+u)}
$$

Depths designated $w_{\text {lim }}^{\left(\rho_{\text {remn(M1,1) }}^{(a l t, d)}, d\right)}$ and $w_{\text {lim }}^{\left(\rho_{\text {remn(M1,1 }}^{(a l t, d)}, u\right)}$ are read at $\rho_{\text {remn(M1,1) }}^{(\text {alt }, d)}$ from the down-milling and upmilling stability diagrams respectively. The sum axial depth of the to and fro passes of the last VC becomes

$$
w_{\text {lim }}^{\left(\rho_{\text {remn }(M 1,1)}^{(a l t, d+u)}\right.}=w_{\text {lim }}^{\left(\rho_{\text {remn(M1,1) }}^{(a l t, d)}, d\right)}+w_{\text {lim }}^{\left(\rho_{\text {remn(M1,1) }}^{(a l t, d)}, u\right)}
$$

The remnant axial depth of the last $\mathrm{VC}$ becomes given as

$$
w_{\text {remn }}^{\left(\rho_{\text {remn }(M 1,1)}^{(\text {alt,d })}, d+u\right)}=l_{d}-f l o o r\left(\frac{l_{d}}{w_{\text {lim }}^{\left(\rho_{\text {remnn(M1,1) }}^{(a l t, d)} d+u\right)}}\right) \times w_{\lim }^{\left(\rho_{\text {remn }(M 1,1)}^{(a l t, d)}, d+u\right)}
$$

The number of passes of the last $\mathrm{VC}$ becomes either

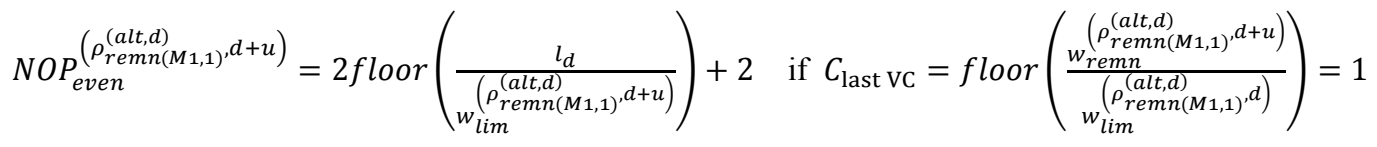

Such that machining time becomes

$$
t_{m}=\frac{l_{l}-D}{v}\left[N O P_{\text {even }}^{(\rho=1,2 f)}+N O P_{\text {alt } 2, \text { total }(M 1,1)}^{(d+u)}+N O P_{\text {even }}^{\left(\rho_{\text {remn }(M 1,1)}^{(\text {alt }, d)} d+u\right)}\right]
$$


or

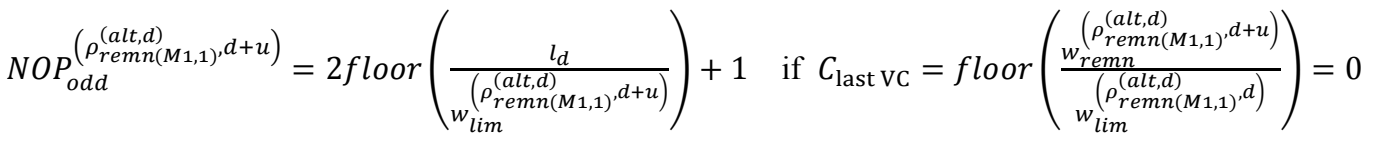

Such that machining time becomes

$$
t_{m}=\frac{l_{l}-D}{v}\left[N O P_{\text {even }}^{(\rho=1,2 f)}+N O P_{\text {alt } 2, \operatorname{total}(M 1,1)}^{(d+u)}+N O P_{\text {odd }}^{\left(\rho_{\text {remn }(M 1,1)}^{(a l t, d)}, d+u\right)}\right]
$$

The eight situations of mode $(1,1)$ to which the presented machining times belong is shown in figure4 in which the red and blue circles in a $\mathrm{VC}$ respectively represent the side of start and completion of the VC.

\subsection{Machining time of mode $(1,2)$}

The number of passes for the first $\mathrm{VC}$ of this mode is odd thus forthwith designated $N O P_{o d d}^{(\rho=1,2 f)}$ and equation (17c) holds. To represent that the first pass (the to pass) of the second $\mathrm{VC}$ is up-milling the chosen parameter coordinate read from up-milling stability diagram is designated $w_{\text {lim }}^{\left(\rho_{\text {lim }}^{(u)}, u\right)}$ and $\rho_{\text {lim }}^{(u)}$. The return down-milling pass (the fro pass) is then carried out at $w_{\text {lim }}^{\left(\rho_{\text {lim }}^{(u)}, d\right)}$ and $\rho_{\text {lim }}^{(u)}$. The sum axial depth of the to and fro passes becomes as given in equation (27). The remnant axial depth of the second $\mathrm{VC}$ after the permissible whole number of to and fro axial depths is computed as given in equation (28). The number of passes of the bivariately optimized second VC becomes as given in equation (29a or 29b) but with the conditions now respectively represented as $C_{2^{n d_{V C}}}=$ floor $\left(w_{\text {remn }}^{\left(\rho_{\text {lim }}^{(u)}, u+d\right)} / w_{\text {lim }}^{\left(\rho_{\text {lim }}^{(u)}, u\right)}\right)=1 \quad$ or $\quad C_{2^{n d} d_{V C}}=$ floor $\left(w_{\text {remn }}^{\left(\rho_{\text {lim }}^{(u)}, u+d\right)} / w_{\text {lim }}^{\left(\rho_{\text {lim }}^{(u)}, u\right)}\right)=0$. Suppose equation (29a) holds, the number of bivariately optimized VCs for which $\rho_{\text {lim }}^{(u)}$ becomes

$$
N O P_{\text {even,total }(M 1,2)}^{\left(\rho_{\text {lim }}^{(u)}, u+d\right)}=\text { floor }\left(\frac{l_{w}-D}{\rho_{\text {lim }}^{(u)} D}\right) N O P_{\text {even }}^{\left(\rho_{\text {lim }}^{(u)}, u+d\right)}
$$

The radial immersion for the last VC that also starts at point 2 is given by

$$
\rho_{\text {remn }(M 1,2)}^{(u)}=\frac{l_{w}}{D}-1-\text { floor }\left(\frac{l_{w}-D}{\rho_{\text {lim }}^{(u)}}\right) \rho_{\text {lim }}^{(u)}
$$

Axial depths $w_{\text {lim }}^{\left(\rho_{\text {remn(M1,2) }}^{(u)}, u\right)}$ and $w_{\text {lim }}^{\left(\rho_{\text {remn(M1,2) }}^{(u)}, d\right)}$ are read from the stability diagram of up-milling and downmilling respectively at fixed radial immersion $\rho_{\text {remn(M1,2) }}^{(u)}$. The sum axial depth of the to and fro passes of the last VC becomes

$$
w_{\lim }^{\left(\rho_{\text {remn }(M 1,2)}^{(u)}, u+d\right)}=w_{\lim }^{\left(\rho_{\text {remn }(M 1,2)}^{(u)}, u\right)}+w_{\lim }^{\left(\rho_{\text {remn(M1,2) }}^{(u)}, d\right)}
$$

The remnant axial depth of the last $\mathrm{VC}$ after the permissible whole number of to and fro axial depths is computed as

$$
w_{\text {remn }}^{\left(\rho_{\text {remn }(M 1,2)}^{(u)}, u+d\right)}=l_{d}-\text { floor }\left(\frac{l_{d}}{w_{\text {lim }}^{\left(\rho_{\text {remn }(M 1,2)}^{(u)}, u+d\right)}}\right) \times w_{\text {lim }}^{\left(\rho_{\text {remn }(M 1,2)}^{(u)}, u+d\right)}
$$


Chigbogu Ozoegwu, Sunday Ofochebe \& Chinedu Ezugwu, Int J Adv Manuf Technol The final publication is available at Springer via http://dx.doi.org/[DOI 10.1007/s00170-015-8108-9]

(a)

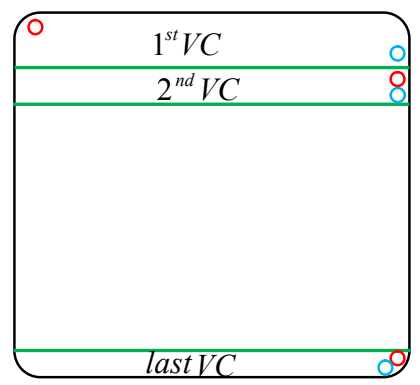

(d)

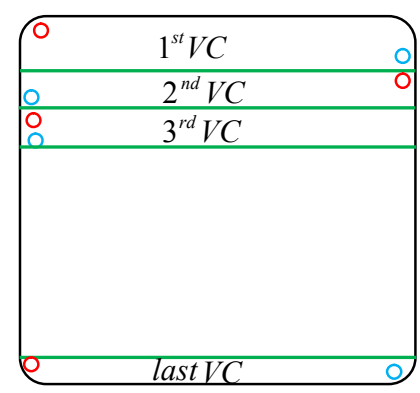

$(\mathrm{g})$

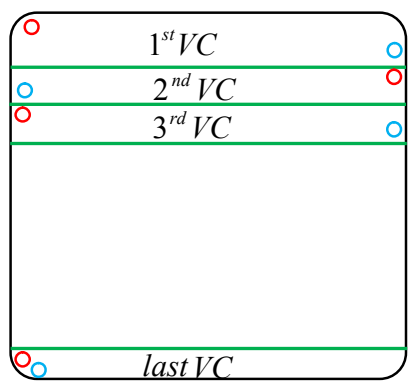

(b)

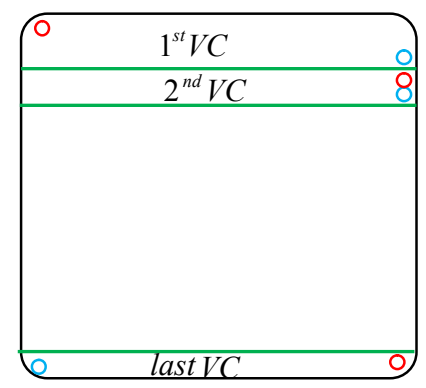

(e)

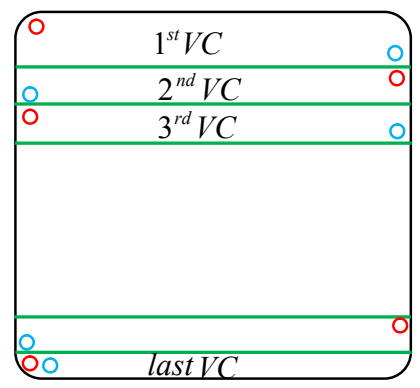

(h)

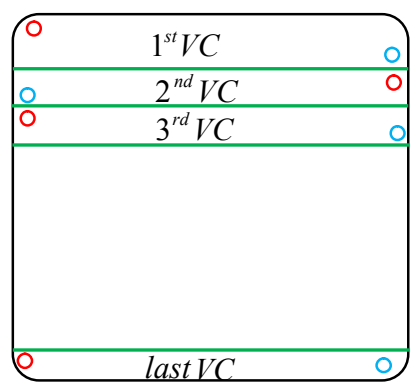

(c)

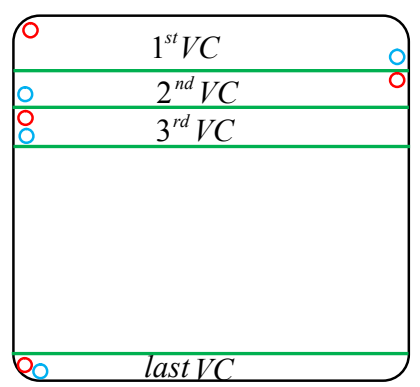

(f)

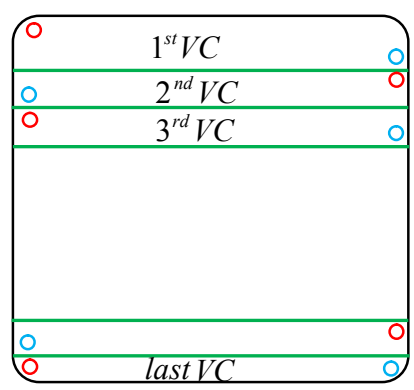

Figure5. the conditions for machining times of mode $(1,2)$ (a) equations $(29 a, 53 a, 54 a)$, (b) equations $(29 a$, $53 \mathrm{~b}, 54 \mathrm{~b})$, (c) equations (29b, 20a, 59a, 60a), (d) equations (29b, 20a, 59b, 60b), (e) equations (29b, 20b, 61, 65a, 66a), (f) equations (29b, 20b, 61, 65b, 66b), (g) equations (29b, 20b, 67, 71a, 72a), (h) equations (29b, 20b, $67,71 b, 72 b)$

The number of passes of the last $\mathrm{VC}$ becomes either

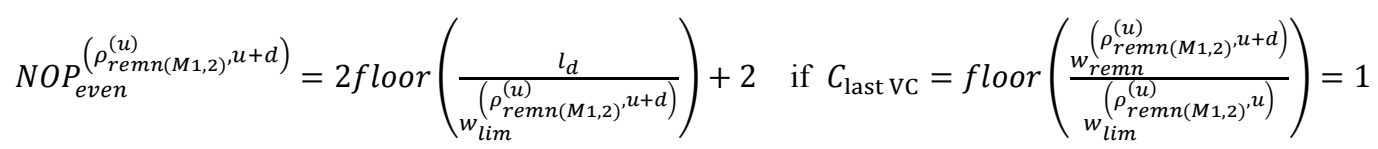

such that the machining time becomes

$$
t_{m}=\frac{l_{l}-D}{v}\left[N O P_{\text {odd }}^{(\rho=1,2 f)}+N O P_{\text {even, total }(M 1,2)}^{\left(\rho_{\text {lim }}^{(u)}, u+d\right)}+N O P_{\text {even }}^{\left(\rho_{\text {rem }(M 1,2)}^{(u)}, u+d\right)}\right]
$$

or the number of passes of the last $\mathrm{VC}$ becomes 


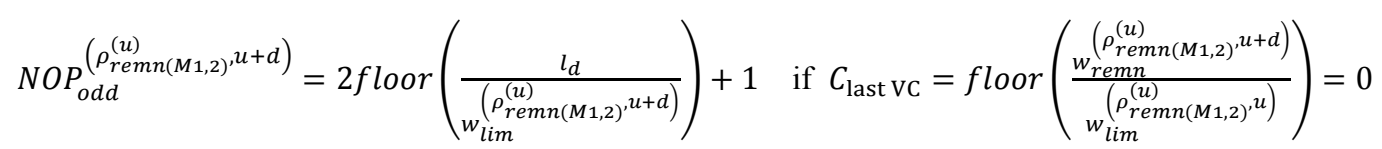

such that the machining time becomes

$$
t_{m}=\frac{l_{l}-D}{v}\left[N O P_{o d d}^{(\rho=1,2 f)}+N O P_{\text {even, }, \operatorname{total}(M 1,2)}^{\left(\rho_{\text {lim }}^{(u)}, u+d\right)}+N O P_{\text {odd }}^{\left(\rho_{\text {remn }(M 1,2)}^{(u)}, u+d\right)}\right]
$$

For the case where equation (29b) holds the first pass of the third VC is in down-milling mode. A pair of limiting axial and radial depths of cut designated respectively as $w_{\text {lim }}^{\left(\rho_{l i m}^{(d)}, d\right)}$ and $\rho_{\text {lim }}^{(d)}$ is chosen for the first down-milling pass (the to pass) of the third VC. The return up-milling pass (the fro pass) is then carried out at $w_{\text {lim }}^{\left(\rho_{l i m}^{(d)}, u\right)}$ and $\rho_{\text {lim }}^{(d)}$. The sum axial depth of the to and fro passes becomes equation (18). The remnant axial depth of the third VC after the permissible whole number of to and fro axial depths is computed as given in equation (19). The number of passes of the bivariately optimized third VC becomes as given in equation (20a or 20b) but with the conditions now respectively represented as $C_{3^{r d}}$ VC $=$ floor $\left(w_{\text {remn }}^{\left(\rho_{\text {ldm }}^{(d)}, d+u\right)} / w_{\text {lim }}^{\left(\rho_{\text {lim, }}^{(d)}, d\right)}\right)=1$ or $C_{3} r d V C=$ floor $\left(w_{\text {remn }}^{\left(\rho_{\text {lim }}^{(d)}, d+u\right)} / w_{\text {lim }}^{\left(\rho_{\text {lim }}^{(d)}, d\right)}\right)=0$. Suppose equation (20a) holds, the number of bivariately optimized VCs for which $\rho_{\text {lim }}^{(d)}$ becomes

$$
N O P_{\text {even, }, \text { total }(M 1,2)}^{\left(\rho_{\text {lim }}^{(d)}, d+u\right)}=\text { floor }\left(\frac{l_{w}-D-\rho_{\text {lim }}^{(u)} D}{\rho_{\text {lim }}^{(d)} D}\right) N O P_{\text {even }}^{\left(\rho_{\text {lim }}^{(d)}, d+u\right)}
$$

The radial immersion for the remnant $\mathrm{VC}$ that also starts at point 1 is given by

$$
\rho_{\text {remn }(M 1,2)}^{(d)}=\frac{l_{w}}{D}-1-\rho_{\text {lim }}^{(u)}-\text { floor }\left(\frac{l_{w}-D-\rho_{\text {lim }}^{(u)}}{\rho_{\text {lim }}^{(d)}}\right) \rho_{\text {lim }}^{(d)}
$$

Axial depths $w_{\text {lim }}^{\left(\rho_{\text {remn }(M 1,2)^{\prime}}^{(d)}, d\right)}$ and $w_{\text {lim }}^{\left(\rho_{\text {remn }(M 1,2)}^{(d)}, u\right)}$ are read from the stability diagram of down-milling and upmilling respectively at fixed radial immersion $\rho_{\text {remn(M1,2) }}^{(d)}$. The sum axial depth of the to and fro passes of the last VC becomes

$$
w_{\text {lim }}^{\left(\rho_{\text {remn }(M 1,2)}^{(d)}, d+u\right)}=w_{\text {lim }}^{\left(\rho_{\text {remn }(M 1,2)}^{(d)}, d\right)}+w_{\text {lim }}^{\left(\rho_{\text {remn }(M 1,2)}^{(d)}, u\right)}
$$

The remnant axial depth of the last $\mathrm{VC}$ after the permissible whole number of to and fro axial depths is computed as

$$
w_{\text {remn }}^{\left(\rho_{\text {remn }(M 1,2)}^{(d)}\right)^{d+u)}}=l_{d}-\text { floor }\left(\frac{l_{d}}{w_{\text {lim }}^{\left(\rho_{\text {remn }(M 1,2)}^{(d)}, d+u\right)}}\right) \times w_{\text {lim }}^{\left(\rho_{\text {remn }(M 1,2)}^{(d)}, d+u\right)}
$$

The number of passes of the last VC becomes either

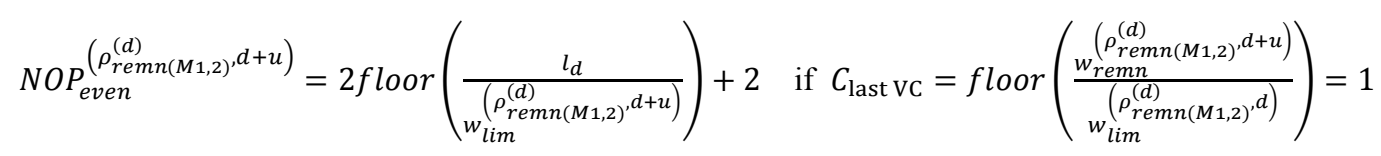

such that the machining time becomes 
Chigbogu Ozoegwu, Sunday Ofochebe \& Chinedu Ezugwu, Int J Adv Manuf Technol The final publication is available at Springer via http://dx.doi.org/[DOI 10.1007/s00170-015-8108-9]

$$
t_{m}=\frac{l_{l}-D}{v}\left[N O P_{o d d}^{(\rho=1,2 f)}+N O P_{o d d}^{\left(\rho_{\text {lim }}^{(u)}, u+d\right)}+N O P_{\text {even,total }(M 1,2)}^{\left(\rho_{\text {lim }}^{(d)}, d+u\right)}+N O P_{\text {even }}^{\left(\rho_{\text {remn(M1,2) }}^{(d)}, d+u\right)}\right]
$$

or the number of passes of the remnant VC becomes either

$$
N O P_{o d d}^{\left(\rho_{\text {remn }(M 1,2)}^{(d)}, d+u\right)}=2 f \operatorname{loor}\left(\frac{l_{d}}{w_{\text {lim }}^{\left(\rho_{\text {remn }(M 1,2)}^{(d)}, d+u\right)}}\right)+1 \quad \text { if } C_{\text {last VC }}=f \operatorname{loor}\left(\frac{w_{\text {remn }}^{\left(\rho_{\text {remn }(M 1,2)}^{(d)}, d+u\right)}}{w_{\text {lim }}^{(d)}\left(\rho_{\text {remn }(M 1,2)^{\prime}}, d\right)}\right)=0
$$

such that the machining time becomes

$$
t_{m}=\frac{l_{l}-D}{v}\left[N O P_{o d d}^{(\rho=1,2 f)}+N O P_{o d d}^{\left(\rho_{\text {lim }}^{(u)}, u+d\right)}+N O P_{\text {even, total }(M 1,2)}^{\left(\rho_{\text {lim }}^{(d)}, d+u\right)}+N O P_{o d d}^{\left(\rho_{\text {remn }(M 1,2)}^{(d)}, d+u\right)}\right]
$$

If equation (20b) holds instead then $N O P_{o d d}^{\left(\rho_{\text {lim }}^{(u)}, u+d\right)}$ as given in equation $(29 \mathrm{~b})$ and $N O P_{o d d}^{\left(\rho_{\text {lim }}^{(d)}, d+u\right)}$ as given in equation (20b) will alternate. The alternation is from the second VC. Under this condition the radial immersion remaining after the bivariately optimized VCs now designated as $\rho_{\text {remn }}^{(a l t, u+d)}=\rho_{\text {remn }}^{(a l t, d+u)}$ as in equation (36). The total number of passes of bivariately optimized VCs becomes

$$
\begin{aligned}
& N O P_{\text {alt1,total }(M 1,2)}^{(u+d)} \\
& =\left[N O P_{o d d}^{\left(\rho_{\text {lim }}^{(u)}, u+d\right)}+N O P_{o d d}^{\left(\rho_{\text {lim }}^{(d)}, d+u\right)}\right] \text { floor }\left(\frac{l_{w}-D}{\left(\rho_{\text {lim }}^{(u)}+\rho_{\text {lim }}^{(d)}\right) D}\right) \\
& +N O P_{o d d}^{\left(\rho_{\text {lim }}^{(u)}, u+d\right)} \quad \text { if } C_{00, \text { last1or 2VCs }}=\text { floor }\left(\frac{\rho_{\text {remn }}^{(a l t, u+d)}}{\rho_{\text {lim }}^{(u)}}\right)=1
\end{aligned}
$$

Radial immersion of the last VC becomes

$$
\rho_{\text {remn }(M 1,2)}^{(a l t, d)}=\rho_{\text {remn }}^{(a l t, u+d)}-\rho_{\text {lim }}^{(u)}
$$

Then axial depths $w_{\text {lim }}^{\left(\rho_{\text {remn(M1,2) }}^{(a l t, d)}, d\right)}$ and $w_{\text {lim }}^{\left(\rho_{\text {remn(M1,2) }}^{(a l t, d)}, u\right)}$ are chosen at $\rho_{\text {remn(M1,2) }}^{(\text {alt }, d)}$ from the down-milling pass and up-milling stability diagrams respectively. The sum axial depth of the to and fro passes of the last VC becomes

$$
w_{\text {lim }}^{\left(\rho_{\text {remn }(M 1,2)}^{(a l t, d)}, d+u\right)}=w_{\text {lim }}^{\left(\rho_{\text {remn }(M 1,2)}^{(a l t, d)}, d\right)}+w_{\text {lim }}^{\left(\rho_{\text {remn(M1,2) }}^{(a l t, d)}, u\right)}
$$

The remnant axial depth of the last $\mathrm{VC}$ becomes

$$
w_{\text {remn }}^{\left(\rho_{\text {remn(M1,2) }}^{(a l t, d)}, d+u\right)}=l_{d}-\text { floor }\left(\frac{l_{d}}{w_{\text {lim }}^{\left(\rho_{\text {remn }(M 1,2)}^{(a l t, d)}, d+u\right)}}\right) \times w_{l i m}^{\left(\rho_{\text {remn }(M 1,2)}^{(a l t, d)}, d+u\right)}
$$

The number of passes of the last $\mathrm{VC}$ becomes either

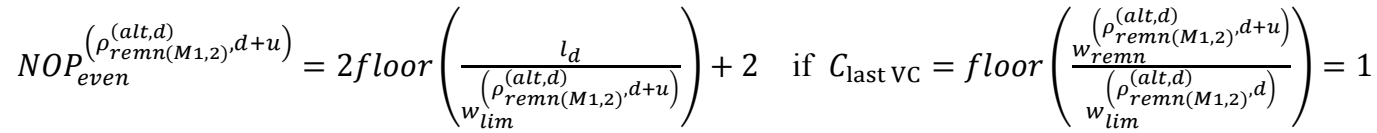

Such that machining time becomes 
Chigbogu Ozoegwu, Sunday Ofochebe \& Chinedu Ezugwu, Int J Adv Manuf Technol The final publication is available at Springer via http://dx.doi.org/[DOI 10.1007/s00170-015-8108-9]

$$
t_{m}=\frac{l_{l}-D}{v}\left[N O P_{\text {odd }}^{(\rho=1,2 f)}+N O P_{\text {alt } 1, \operatorname{total}(M 1,2)}^{(u+d)}+N O P_{\text {even }}^{\left(\rho_{\text {remn }(M 1,2)}^{(\text {alt }, d)}, d+u\right)}\right]
$$

Or the number of passes of the last VC becomes

$$
N O P_{o d d}^{\left(\rho_{\text {remn }(M 1,2)}^{(\text {alt }, d)}, d+u\right)}=2 f \operatorname{loor}\left(\frac{l_{d}}{w_{\text {lim }}^{\left(\rho_{\text {remn }(M 1,2)}^{(\text {alt } d)}, d+u\right)}}\right)+1 \quad \text { if } C_{\text {last VC }}=f \operatorname{loor}\left(\frac{w_{\text {remn }}^{\left(\rho_{\text {remn }(M 1,2)}^{(a l t, d)}, d+u\right)}}{w_{\text {lim }}^{\left(\rho_{\text {remn }(M 1,2)}^{(a l t, d)}\right)}}\right)=0
$$

Such that machining time becomes

$$
t_{m}=\frac{l_{l}-D}{v}\left[N O P_{o d d}^{(\rho=1,2 f)}+N O P_{\text {alt } 1, \operatorname{total}(M 1,2)}^{(u+d)}+N O P_{o d d}^{\left(\rho_{\text {remn(M1,2) }}^{(\text {alt }, d)}, d+u\right)}\right]
$$

Instead of equation (61) the other equation that can hold for the total number of passes of bivariately optimized $\mathrm{VCs}$ is

$$
\begin{gathered}
N O P_{\text {alt } 2, \text { total }(M 1,2)}^{(u+d)}=\left[N O P_{\text {odd }}^{\left(\rho_{\text {lim }}^{(u)}, u+d\right)}+N O P_{\text {odd }}^{\left(\rho_{\text {lim }}^{(d)}, d+u\right)}\right] \text { floor }\left(\frac{l_{w}-D}{\left(\rho_{\text {lim }}^{(u)}+\rho_{\text {lim }}^{(d)}\right) D}\right) \text { if } \\
C_{00, \text { last1or2VCs }}=f \operatorname{loor}\left(\frac{\rho_{\text {remn }}^{(\text {alt }, u+d)}}{\rho_{\text {lim }}^{(u)}}\right)=0
\end{gathered}
$$

Radial immersion of the remnant VC becomes

$$
\rho_{\text {remn }(M 1,2)}^{(a l t, u)}=\rho_{\text {remn }}^{(\text {alt }, u+d)}
$$

The axial depths $w_{\text {lim }}^{\left(\rho_{\text {remn(t, }(M 1,2)}^{(a, u)}\right)}$ and $w_{\text {lim }}^{\left(\rho_{\text {remn(M1,2) }}^{(\text {alt }, u)}\right)}$ at $\rho_{\text {remn(M1,2) }}^{(\text {alt }, u)}$ are chosen from the up-milling pass and down-milling stability diagrams respectively. The sum axial depth of the to and fro passes of the remnant VC becomes

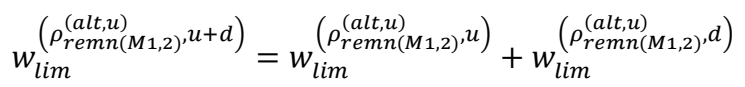

Compute the remnant axial depth of the last $\mathrm{VC}$ as

$$
w_{\text {remn }}^{\left(\rho_{\text {remn(M1,2) }}^{(\text {alt }, u)}, u+d\right)}=l_{d}-f \operatorname{floor}\left(\frac{l_{d}}{w_{\text {lim }}^{\left(\rho_{\text {remn }(M 1,2)}^{(\text {alt }, u+d)}\right)}}\right) \times w_{\text {lim }}^{\left(\rho_{\text {remn }(M 1,2)}^{(a l t, u+d)}, u+d\right)}
$$

The number of passes of the last $\mathrm{VC}$ becomes either

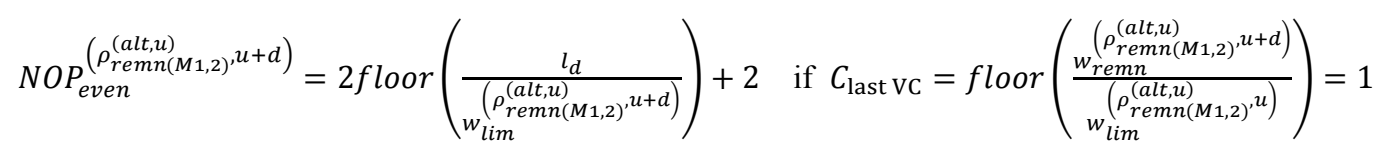

Such that machining time becomes

$$
t_{m}=\frac{l_{l}-D}{v}\left[N O P_{o d d}^{(\rho=1,2 f)}+N O P_{\text {alt } 2, \text { total }(M 1,2)}^{(u+d)}+N O P_{\text {even }}^{\left(\rho_{\text {remn }(M 1,2)}^{(a l t, u)}, u+d\right)}\right]
$$

Or the number of passes of the last VC becomes 


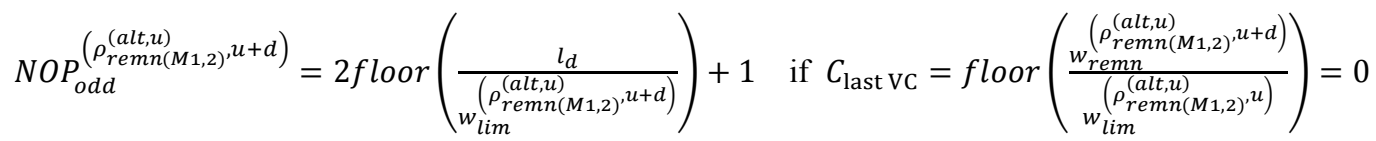

Such that machining time becomes

$$
t_{m}=\frac{l_{l}-D}{v}\left[N O P_{o d d}^{(\rho=1,2 f)}+N O P_{\text {alt } 2, \operatorname{total}(M 1,2)}^{(u+d)}+N O P_{o d d}^{\left(\rho_{\text {remn }(M 1,2)}^{(a l t, u)}, u+d\right)}\right]
$$

The eight situations of mode $(1,2)$ to which the presented machining times belong is shown in figure 5 in which the red and blue circles in a VC respectively represent the side of start and completion of the VC. $C_{00, \text { last1or2VCs }}$

\section{Discussions of Analytical and Numerical Results}

It is seen that there are sixteen possible equations for pocketing time following zigzag toolpath. These possibilities derive from various conditions seen in the development of the equations. Why this is so needs some attention. There two kinds of conditions seen; the kind of condition designated $C_{j} t_{V C}$ where $C$ connotes condition and $j$ the number of the $\mathrm{VC}$ from which the condition derives in the derivation of the equations and the kind of condition designated for example with $C_{00, \text { last1or2vCs }}$ where the zeros in the subscript respectively represent the values of $C_{2^{n d}}{ }_{V C}$ and $C_{3} r d_{V C}$ and "last1or2VCs" represents that the condition is also dependent on the last or last two VCs. Four situations contributing to the number of machining times are spotted. The first three are combination of conditions; $C_{2^{n d}}=1$ together with its implied condition $C_{3^{r d}}=C_{2^{n d}}=1$, $C_{2^{n d}}=0$ together with the condition $C_{3} r d_{V C}=1$ and $C_{2^{n d}}=0$ together with the condition $C_{3} r d_{V C}=0$ while the last situation is the situation occasioned by the condition $C_{00, \text { last1or2vCs. These four situations }}$ multiplicatively associate with two possibilities each of first VC and last VC to give $4 \times 2 \times 2=16$ elements in the functional space of machining time. This is seen to correspond to the number of derived equations. The sixteen equations jointly describe one quantity; the machining time, with the conditions acting as the screening criteria that agree as to which of the functions is applicable given pocket size, tool size and tool regenerative dynamics. The sixteen functions constitute the functional space of zigzag pocketing time. Any element of the functional space becomes the governing function for machining time when conditions associated with it are simultaneously met. The pocketing process on one-way toolpath considered in [77] reflects only one condition; the execution of all active passes is in fixed mode. The total number of possible forms in the functional space of pocketing time then became1. That is why only single equation for pocketing time exists for $\mathrm{VC}$ routine along one-way toolpath in [77].

The pocketing time expressions are generalizations that could be considered more applicable to roughening operations but can be simplified to be applicable in finish processes and conventional method of using fixed depth parameters for all modes of operation encountered in zigzag pocketing. Thus there is no loss of generality in use of the expressions. For example, suppose fixed axial depth $w$ and radial depth $\rho D$ (after the fully immersed $1^{\text {st }} \mathrm{VC}$ and before the last remnant VC) are maintained throughout, also suppose execution of all the VC's start and end at same side of the pocket then the number of passes for each VC is same as $\left[2 f l o o r\left(\frac{l_{d}}{2 w}\right)+\right.$ $2]$ and the total number of passes becomes $\left[1+\right.$ floor $\left.\left(\frac{l_{w}-D}{\rho D}\right)+1\right]$. Since the length of each pass is $l_{l}-D$ the machining time reads

$$
t_{m}=\frac{l_{l}-D}{v}\left[2 \text { floor }\left(\frac{l_{d}}{2 w}\right)+2\right]\left[2+\text { floor }\left(\frac{l_{w}-D}{\rho D}\right)\right]
$$

It is seen that this expression also arises from making the substitutions $\rho_{\text {lim }}^{(d)}=\rho, w_{\text {lim }}^{(\rho=1)}=w_{\text {lim }}^{\left(\rho_{\text {lim }}^{(d)}, d\right)}=$ $w_{\text {lim }}^{\left(\rho_{\text {lim }}^{(d)}, u\right)}=w_{\text {lim }}^{\left(\rho_{\text {remn }}^{(d)}, d\right)}=w_{\text {lim }}^{\left(\rho_{\text {remn }}^{(d)}, u\right)}=w$ in equation (26a) demonstrating that the presented machining time expressions are generalized for roughening, finishing and conventional zig-zag pocketing operations. The other implication is that the presented expressions are still applicable when the limiting conditions are beyond the load capacity of the machine tool leading to prescription of less than limiting depths. 
Numerical computations is carried out on a milling system which was experimentally characterized in the work of Weck et al as cited in [75] and given in table2. The practical inspired feed speed adopted to be used in numerical analysis is $v=0.0025 \mathrm{~ms}^{-1}$. The stability diagram of the system given as limiting axial depth of cut $w_{\text {lim }}$ versus $\Omega$ at up-milling radial immersion $\rho=0.67$ is generated using $r=40$ on 200 by 100 gridded plane after 45 minutes computation and presented in figure6(a). A productive spindle speed within the technological limit of the system is seen to be $12600 \mathrm{rpm}$. The stability limit of up-milling giving limiting radial immersion $\rho_{\text {lim }}$ as a function of limiting axial depth of cut $w_{\text {lim }}$ at the chosen productive spindle speed of $12600 \mathrm{rpm}$ is then generated following the computational flowchart in appendix as presented in figure6(b). The limiting material removal rate given as $M R R_{\text {lim }}=D w_{\text {lim }} \rho_{\text {lim }} v$ is generated as both $M R R_{\text {lim }}$ versus $w_{\text {lim }}$ and $M R R_{\text {lim }}$ versus $\rho_{\text {lim }}$ as respectively presented in figure6(c) and 6(d) with indications of point of maximum $M R R_{\text {lim }}$. Each of the figures 6(b), 6(c) and 6(d) required about 68 minutes computation using $r=80$ on 50 by 50 gridded plane. The point of maximum $M R R_{\text {lim }}$ also indicated on figure6(b) more probably provides the shortest machining time the larger the pocket gets [77]. The maximum $M R R_{\text {lim }}$ can be seen to be occurring at the optimal coordinate $\left(w_{\text {lim }}=0.0048 m\right.$, $\left.\rho_{\text {lim }}=0.856\right)$ thus has the value $M R R_{\text {lim }}=0.01 \times 0.0048 \times 0.856 \times$ $0.0025=1.0272 \times 10^{-7} \mathrm{~m}^{3} \mathrm{~s}^{-1}$.

The equivalent stability diagrams for the down milling operation are shown in figure7. The stability diagram of the system given in figure7(a) as $w_{\text {lim }}$ versus $\Omega$ at $\rho=0.67$ which was generated using $r=40$ on 200 by 100 gridded plane also required 45 minutes computation. A productive spindle speed arising from lobeing effect is seen to be still $12600 \mathrm{rpm}$. Mode of operation does not affect the range of occurrence of the productive speeds [77]. The stability limit of down-milling giving $\rho_{\text {lim }}$ as a function of $w_{\text {lim }}$ at the chosen productive spindle speed of $12600 \mathrm{rpm}$ is then generated as presented in figure7(b). The $M R R_{\text {lim }}$ generated as both $M R R_{\text {lim }}$ versus $w_{\text {lim }}$ and $M R R_{\text {lim }}$ versus $\rho_{\text {lim }}$ as respectively presented in figure7(c) and 7(d) with indications of point of maximum $M R R_{\text {lim }}$. Just like the corresponding diagrams in figure6, each of the diagrams 7(b), 7(c) and 7(d) required about 68 minutes computation using $r=80$ on 50 by 50 gridded plane. The maximum $M R R_{\text {lim }}$ occurs at the coordinate $\left(w_{\text {lim }}=0.0166 \mathrm{~m}, \rho_{\text {lim }}=0.32\right)$ indicated with arrow in diagrams $7(\mathrm{~b}), 7(\mathrm{c})$ and $7(\mathrm{~d})$.

\begin{tabular}{ccc}
\hline $\begin{array}{l}\text { Table2. } \\
\text { et al [78] }\end{array}$ & Numerical parameters for milling process stability analysis. Source; Weck \\
\hline parameter & value & units \\
$\boldsymbol{\omega}_{\boldsymbol{n} \boldsymbol{x}}$ & $2 \pi \times 600 \mathrm{rads}^{-1}$ & $\mathrm{rads}^{-1}$ \\
$\boldsymbol{\omega}_{\boldsymbol{n} \boldsymbol{y}}$ & $2 \pi \times 660 \mathrm{rads}^{-1}$ & $\mathrm{rads}^{-1}$ \\
$\boldsymbol{k}_{\boldsymbol{x}}$ & $5.6 \times 10^{6}$ & $\mathrm{Nm}^{-1}$ \\
$\boldsymbol{k}_{\boldsymbol{y}}$ & $5.6 \times 10^{6}$ & $\mathrm{Nm}^{-1}$ \\
$\boldsymbol{\zeta}_{\boldsymbol{x}}$ & 0.035 & \\
$\boldsymbol{\zeta}_{\boldsymbol{y}}$ & 0.035 & $\mathrm{~kg}$ \\
$\boldsymbol{m}_{\boldsymbol{x}}$ & $k_{x} / \omega_{n x}{ }^{2}$ & $\mathrm{~kg}$ \\
$\boldsymbol{m}_{\boldsymbol{y}}$ & $k_{y} / \omega_{n y}{ }^{2}$ & \\
$\mathbf{N}$ & 3 & $\mathrm{Nm}^{-2}$ \\
$\boldsymbol{C}_{\mathbf{t}}$ & $6 \times 10^{8} \mathrm{~Pa}$ & $\mathrm{Nm}^{-2}$ \\
\hline $\boldsymbol{C}_{\mathbf{n}}$ & $0.07 \times 10^{6} \mathrm{~Pa}$ & \\
\hline
\end{tabular}
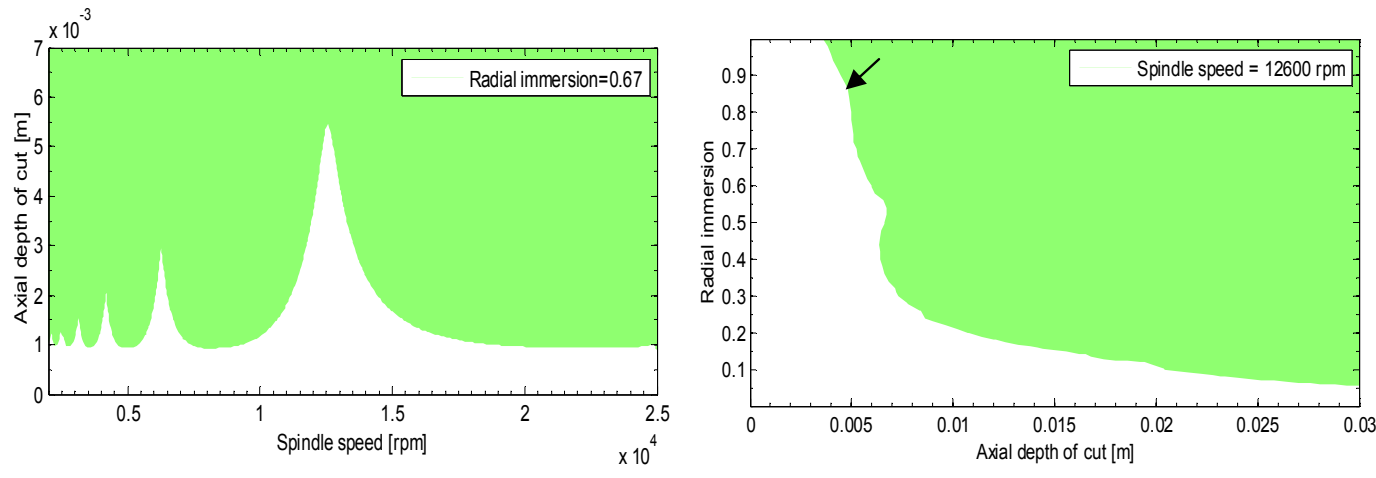
Chigbogu Ozoegwu, Sunday Ofochebe \& Chinedu Ezugwu, Int J Adv Manuf Technol The final publication is available at Springer via http://dx.doi.org/[DOI 10.1007/s00170-015-8108-9]
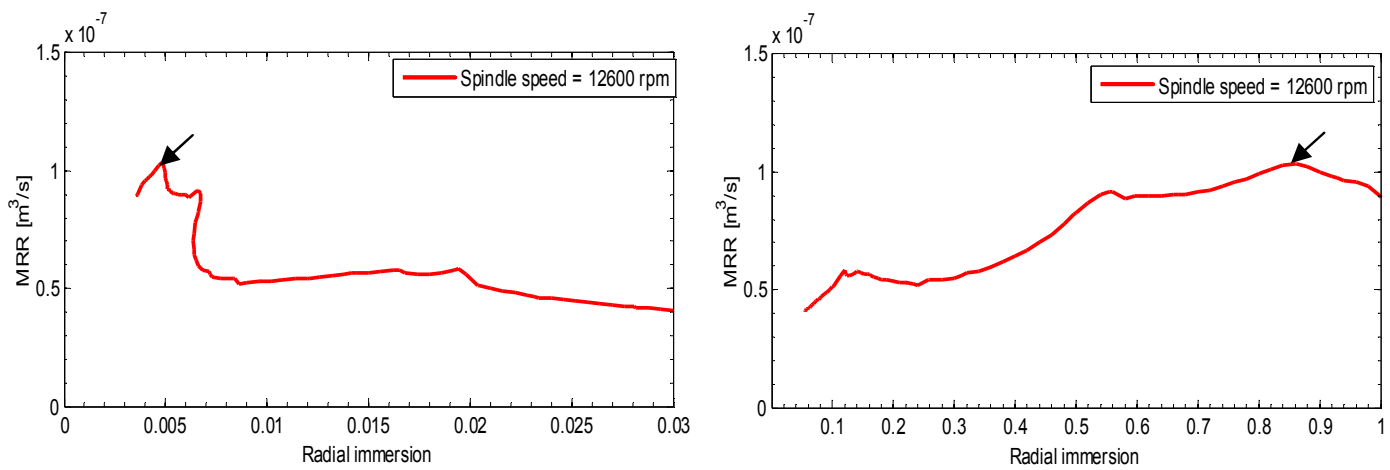

Figure6. The stability limits of 2DOF up-milling on different planes (a) on $\Omega-w$ plane at $\rho=0.67$. It is seen that a very productive spindle speed is $12600 \mathrm{rpm}$ (b) on $w-\rho$ plane at $12600 \mathrm{rpm}$, (c) on $w-M R R$ plane at $12600 \mathrm{rpm}$ and (d) on $\rho-M R R$ plane at $12600 \mathrm{rpm}$. Arrows indicate location of maximum $M R R_{\text {lim }}$.
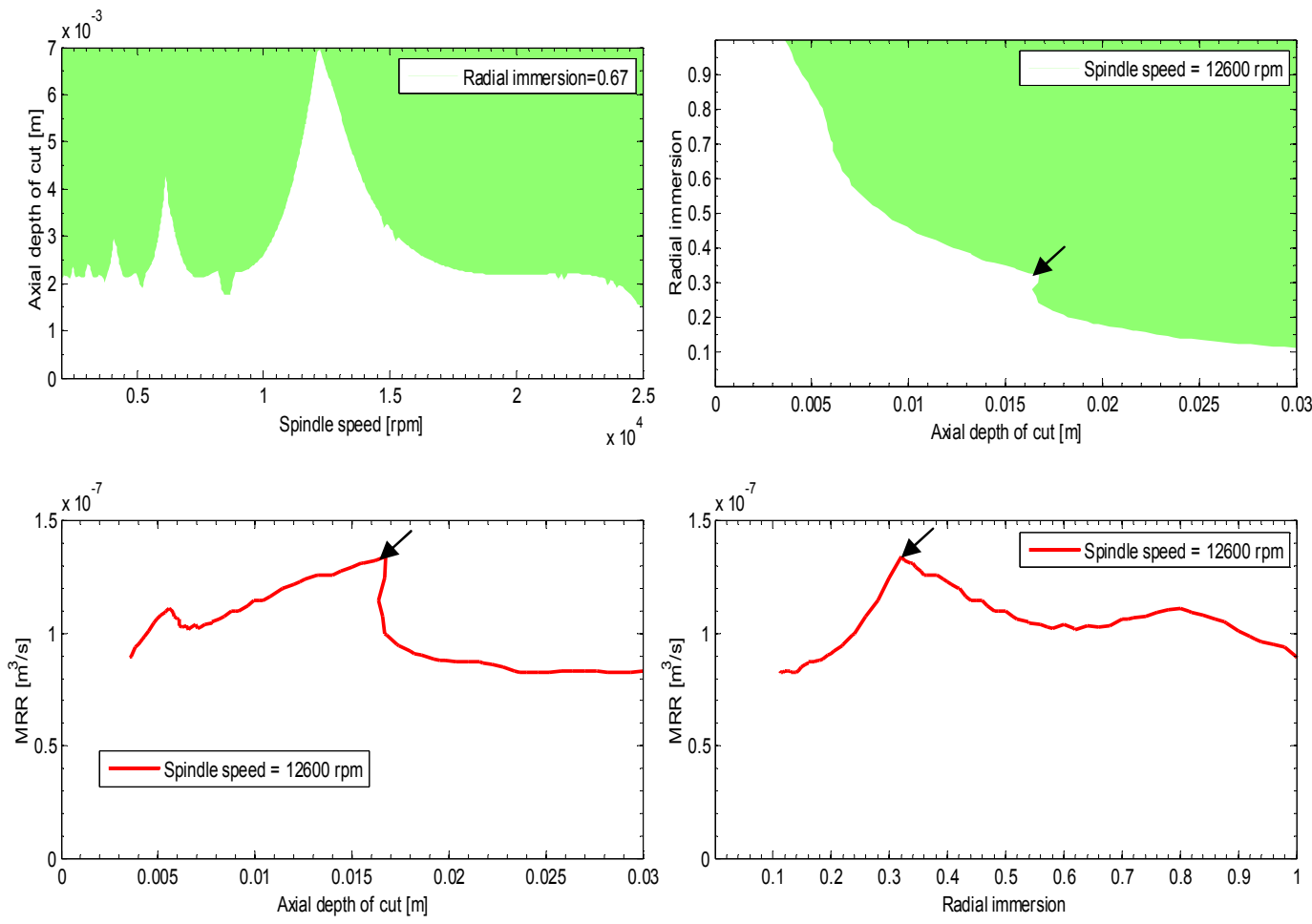

Figure7. The stability limits of 2DOF down-milling on different planes (a) on $\Omega-w$ plane at $\rho=0.67$. It is seen that a very productive spindle speed is $12600 \mathrm{rpm}$ (b) on $w-\rho$ plane at $12600 \mathrm{rpm}$, (c) on $w-M R R$ plane at $12600 \mathrm{rpm}$ and (d) on $\rho-M R R$ plane at $12600 \mathrm{rpm}$. Arrows indicate location of maximum $M R R_{\text {lim }}$.

The general computational procedure for minimizing time of pocket end-milling following zigzag toolpaths prescribed continuously along chatter stability limit is:

i. $\quad$ Choose 3-dimensinal coordinate pairs; $\left(\rho_{\text {lim }}^{(d)}, w_{\text {lim }}^{\left(\rho_{\text {lim }}^{(d)}, d\right)}, w_{\text {lim }}^{\left(\rho_{\text {lim }}^{(d)}, u\right)}\right)$ and $\left(\rho_{\text {lim }}^{(u)}, w_{\text {lim }}^{\left(\rho_{\text {lim }}^{(u)}, u\right)}, w_{\text {lim }}^{\left(\rho_{\text {lim }}^{(u)}, d\right)}\right)$ from the down- and up-milling stability limits. Considering load specifications of the tool/spindle system.

ii. Compute the conditions and then use the results to fix the effective expressions for pocketing time. The rule obeyed in analysis of the conditions is as follows; if $C_{2^{n d}}{ }_{V C}=1$ ignore $C_{3} r d_{V C}$ and look for the next $C_{\text {last VC }}$ but if $C_{2^{n d}}=0$ look for $C_{3} r d_{V C}$, if $C_{3^{r d}}=1$ ignore $C_{00, \text { last1or2VCs }}$ and look for the next $C_{\text {last VC }}$ else if $C_{3}{ }^{r d_{V C}}=0$ look for both $C_{00, \text { last1or2VCs }}$ and $C_{\text {last VC }}$. The sixteen 
combinations of conditions and the corresponding effective expressions for pocketing time are summarized in table 3 below

iii. The terms of the effective expression for pocketing time are computed and numerical values inserted to give the machining time

iv. The best in terms of smallest machining time of several possible coordinates can then be selected for a given pocket dimensions, tool dimensions and chatter dynamic parameters.

The limiting parameters $\left(\rho_{\text {lim }}^{(d)}=0.2, w_{\text {lim }}^{\left(\rho_{\text {lim }}^{(d)}, d\right)}=0.0167, w_{\text {lim }}^{\left(\rho_{\text {lim }}^{(d)}, u\right)}=0.0105\right)$ and $\left(\rho_{\text {lim }}^{(u)}=0.2, w_{\text {lim }}^{\left(\rho_{\text {lim }}^{(u)}, u\right)}=\right.$ $\left.0.0105, w_{\text {lim }}^{\left(\rho_{\text {lim }}^{(u)}, d\right)}=0.0167\right)$ are chosen for the first numerical study. The dimensions of the pocket are $l_{w} / D=15.33, l_{l}=3 \mathrm{~cm}, l_{d}=3 \mathrm{~cm}$, where $D=1 \mathrm{~cm}$ is the toll diameter and $v=0.0025 \mathrm{~m} / \mathrm{s}$ is the feed speed. The conditions are tested as follows; it is seen from any of figure $6 \mathrm{~b}$ or figure $7 \mathrm{~b}$ that $w_{\text {lim }}^{(\rho=1)}=0.0035 \mathrm{~m}$. Making use of equation (17a) it is found that $w_{r e m n}^{(\rho=1,2 f)}=0.002 m$. The $C_{1} s t V C$ is then computed as 0 using its expression in any of equations $(17 \mathrm{~b}$ or $17 \mathrm{c})$. This means that the pocketing operation belongs to mode $(1,2)$. Then compute $w_{\text {lim }}^{\left(\rho_{\text {lim }}^{(u)}, u+d\right)}$ using equation (27) to give $0.0272 \mathrm{~m}$. Making use of equation (28) it is found that $w_{\text {remn }}^{\left(\rho_{\text {lim }}^{(u)}, u+d\right)}=0.0028 m$. The $C_{2^{n d}}$ is then computed as 0 using its expression in any of equations (29a or 29b). The depths $w_{\text {lim }}^{\left(\rho_{\text {lim }}^{(d)}, d+u\right)}$ and $w_{\text {remn }}^{\left(\rho_{\text {lim }}^{(d)}, d+u\right)}$ are computed as 0.0272 and 0.0028 using equations (18) and (19) respectively. The $C_{3} r d_{V C}$ is then computed as 0 using its expression in any of equations (20a or 20b). Since both $C_{2^{n d_{V C}}}$ and $C_{3^{r d_{V C}}}$ are zero the condition $C_{00 \text {,last1or2VCs }}$ is then computed by computing $\rho_{\text {remn }}^{(\text {alt } u+d)}$ as 0.3300 using equation (36) and then using expression for $C_{00, \text { last1or2VCs }}$ in equation (61) to get $C_{00, \text { last1or2VCs }}=1$. Then using Equation(62) gives $\rho_{\text {remn(M1,2) }}^{(\text {alt }, d)}=0.13$. The axial depths $w_{\text {lim }}^{\left(\rho_{\text {remn(M1,2) }}^{(\text {alt }, d)}\right)}$ and $w_{\text {lim }}^{\left(\rho_{\text {remn(M1,2) }}^{(\text {allt,d })}, u\right)}$ are chosen at $\rho_{\text {remn(M1,2) }}^{(\text {alt,d })}$ from the down-milling pass and up-milling stability diagrams as 0.026 and 0.0173 respectively. The depths $w_{\text {lim }}^{\left(\rho_{\text {remn(M1,2) }}^{(\text {alt }, d)}, d+u\right)}$ and $w_{\text {remn }}^{\left(\rho_{\text {remn(M1,2) }}^{(\text {alt,d })}, d+u\right)}$ are computed as 0.0433 and 0.03 using equations (18) and (19) respectively. The $C_{\text {last } V C}$ is then computed as 1 using its expression in any of equations (65a or 65b). The computed conditions are listed as follows; $C_{1^{s t} V C}=0, C_{2^{n d}}=0, C_{3} r d_{V C}=0, C_{00, \text { last1or2VCs }}=1$ and $C_{\text {last VC }}=1$ given that the applicable expression for pocketing time is Equation (66a). The terms in equation (66a) are computed as $N O P_{\text {odd }}^{(\rho=1)}=9, N O P_{\text {alt } 1, \operatorname{total}(M 1,2)}^{(u+d)}=213$ and $N O P_{\text {even }}^{\left(\rho_{\text {remn(M1,2) }}^{(\text {alt }, d) u}\right)}=2$ leading to pocketing time $t_{m}=1792 \mathrm{~s}$. If the pocket is created instead with one-way down-milling toolpaths the machining time established for $\mathrm{VC}$ in [77] gives $t_{m}=2368 \mathrm{~s}$ while for one-way up-milling toolpaths the machining time becomes $t_{m}=3504 \mathrm{~s}$. It is seen that zigzag toolpaths has reduced the pocketing time of one-way down-milling toolpaths by $24.3243 \%$ and that of one-way up-milling toolpaths $48.8584 \%$. The limiting parameters $\left(\rho_{\text {lim }}^{(d)}=\right.$ $\left.0.8, w_{\text {lim }}^{\left(\rho_{\text {lim }}^{(d)}, d\right)}=0.0057, w_{\text {lim }}^{\left(\rho_{\text {lim }}^{(d)}, u\right)}=0.005\right)$ and $\left(\rho_{\text {lim }}^{(u)}=0.8, w_{\text {lim }}^{\left(\rho_{\text {lim }}^{(u)}, u\right)}=0.005, w_{\text {lim }}^{\left(\rho_{\text {lim }}^{(u)}, d\right)}=0.0057\right)$ are chosen for the second numerical study. Following similar procedure the computed conditions are listed as follows; $C_{1} s_{V C}=0, C_{2^{n d}}=1$, and $C_{\text {last } V C}=1$ given that the applicable expression for pocketing time is Equation (54a). Making use of values $\rho_{\text {remn(M1,2) }}^{(u)}=0.73, w_{\text {lim }}^{\left(\rho_{\text {remn(M1,2) }}^{(u)}, u\right)}=0.0051$ and $w_{\lim }^{\left(\rho_{\text {remn(M1,2) }}^{(u)}, d\right)}=$ 0.0059 the terms in equation (64) are computed as $N O P_{\text {odd }}^{(\rho=1)}=9, \quad \operatorname{NOP}_{\text {even, }, \text { total }(M 1,2)}^{\left(\rho_{\text {lim }}^{(u)}, u+d\right)}=102$ and $N O P_{\text {even }}^{\left(\rho_{\text {remn(M1,2) }}^{(u)}, u+d\right)}=6$ leading to pocketing time $t_{m}=936 \mathrm{~s}$. The method in [77] gives $t_{m}=1792 \mathrm{~s}$ for both one-way down-milling and one-way up-milling toolpaths. It is seen that zigzag toolpaths has reduced this pocketing time of one-way toolpaths by $47.7679 \%$. The third numerical study combines the points of maximum $M R R_{\text {lim }}$ for the both down- and up-milling thus the chosen limiting parameters become $\left(\rho_{\text {lim }}^{(d)}=0.32, w_{\text {lim }}^{\left(\rho_{\text {lim }}^{(d)}, d\right)}=0.0166 m, w_{\text {lim }}^{\left(\rho_{\text {lim }}^{(d)}, u\right)}=0.0072\right)$ and $\left(\rho_{\text {lim }}^{(u)}=0.856, w_{\text {lim }}^{\left(\rho_{\text {lim }}^{(u)}, u\right)}=0.0048 m, w_{\text {lim }}^{\left(\rho_{\text {lim }}^{(u)}, d\right)}=0.005\right)$. The computed conditions are listed as follows; $C_{1}^{s t_{V C}}=0, C_{2^{n d} V C}=0, C_{3}^{r d_{V C}}=0, C_{00 \text {,last1or2VCs }}=0\left(\right.$ where $\left.\rho_{\text {remn(M1,2) }}^{(\text {alt } u)}=0.2180\right)$ and $C_{\text {last } V C}=0$ given that the applicable expression for pocketing time is Equation (72b). The terms in equation (72b) are computed 
$N O P_{\text {odd }}^{(\rho=1)}=9, N O P_{\text {alt } 2, \text { total }(M 1,2)}^{(u+d)}=120$ and $N O P_{\text {odd }}^{\left(\rho_{\text {remn(M1,2) }}^{(a l t, u+d)}, u+d\right)}=3$ leading to pocketing time $t_{m}=1056 \mathrm{~s}$. The method in [77] gives $t_{m}=1504 \mathrm{~s}$ for both one-way down-milling and $t_{m}=1936$ for one-way up-milling toolpaths. This means that zigzag toolpaths that combines the points of maximum $M R R_{\text {lim }}$ of both down- and up-milling processes has reduced this pocketing time of one-way down-milling toolpaths at maximum $M R R_{\text {lim }}$ by $29.7872 \%$ and has reduced this pocketing time of one-way up-milling toolpaths at maximum $M R R_{\text {lim }}$ by $45.4545 \%$. It is seen that the combined points of maximum $M R R_{\text {lim }}$ of both down- and up-milling processes in zigzag pocking has not provided the minimum machining time. This is because of geometric restriction. The specific reason is that the $M R R_{\text {lim }}$ of the numerous bivariately optimized passes between the first and last VCs for the zigzag toolpath that combines the maxima of $M R R_{\text {lim }}$ for both down- and up-milling are $M R R_{\text {lim }}=$ $0.01 \times 0.0166 \times 0.32 \times 0.0025=1.3280 \times 10^{-7} \mathrm{~m}^{3} \mathrm{~s}^{-1}$ at the point of maximum $\operatorname{MRR}_{\text {lim }}\left(\rho_{\text {lim }}^{(d)}=\right.$ $\left.0.32, w_{\text {lim }}^{\left(\rho_{\text {lim }}^{(d)}, d\right)}=0.0166 m\right) \quad$ for $\quad$ down-milling, $\quad M R R_{\text {lim }}=0.01 \times 0.0072 \times 0.32 \times 0.0025=0.576 \times$ $10^{-7} \mathrm{~m}^{3} \mathrm{~s}^{-1}$ at the point of non-maximum $\operatorname{MRR}_{\text {lim }}\left(\rho_{\text {lim }}^{(d)}=0.32, w_{\text {lim }}^{\left(\rho_{\text {lim }}^{(d)}, u\right)}=0.0072\right), M R R_{\text {lim }}=0.01 \times$ $0.0048 \times 0.856 \times 0.0025=1.0272 \times 10^{-7} \mathrm{~m}^{3} \mathrm{~s}^{-1}$ at the point of maximum $M R R_{\text {lim }}$ $\left(\rho_{\text {lim }}^{(u)}=0.856, w_{\text {lim }}^{\left(\rho_{\text {lim }}^{(u)}, u\right)}=0.0048 m,\right)$ for up-milling and $M R R_{\text {lim }}=0.01 \times 0.005 \times 0.856 \times 0.0025=$ $1.07 \times 10^{-7} \mathrm{~m}^{3} \mathrm{~s}^{-1}$ at the point of non-maximum $\operatorname{MRR}_{\text {lim }}\left(\rho_{\text {lim }}^{(u)}=0.856, w_{\text {lim }}^{\left(\rho_{\text {lim }}^{(u)}, d\right)}=0.005\right)$ giving the average of these $M R R_{\text {lim }}$ as $1.0003 \times 10^{-7} \mathrm{~m}^{3} \mathrm{~s}^{-1}$ but for the case of second numerical study the average of these $M R R_{\text {lim }}$ becomes $1.07 \times 10^{-7} \mathrm{~m}^{3} \mathrm{~s}^{-1}$. It is seen that average value of the latter is bigger thus provides less pocketing time.

It is seen that zigzag toolpath is much more time saving than either of one-way toolpaths. This is expected because the zigzag toolpath utilizes the stability limit of the system better by maintaining continuously optimized to and fro passes while the fro passes of either of the one-way pocketing operation studied in [77] are idle passes that delay the operation.

\begin{tabular}{|c|c|c|c|c|c|}
\hline \multicolumn{6}{|c|}{$\begin{array}{l}\text { Table3. The sixteen combinations of conditions and the corresponding effective expressions for pocketing } \\
\text { time }\end{array}$} \\
\hline Equation & $C_{1^{s t}}{ }_{V C}$ & $C_{2^{n d}}$ & $C_{3} r d_{V C}$ & $C_{00, \text { last1or2VCs }}$ & $C_{\text {last VC }}$ \\
\hline $26 a$ & 1 & 1 & - & - & 1 \\
\hline $26 b$ & 1 & 1 & - & - & 0 \\
\hline $35 a$ & 1 & 0 & 1 & - & 1 \\
\hline $35 b$ & 1 & 0 & 1 & - & 0 \\
\hline $42 a$ & 1 & 0 & 0 & 1 & 1 \\
\hline $42 b$ & 1 & 0 & 0 & 1 & 0 \\
\hline $48 \mathrm{a}$ & 1 & 0 & 0 & 0 & 1 \\
\hline $48 b$ & 1 & 0 & 0 & 0 & 0 \\
\hline \multicolumn{6}{|c|}{ mode $(1,2)$} \\
\hline $54 a$ & 0 & 1 & - & - & 1 \\
\hline 54b & 0 & 1 & - & - & 0 \\
\hline $60 a$ & 0 & 0 & 1 & - & 1 \\
\hline $60 \mathrm{~b}$ & 0 & 0 & 1 & - & 0 \\
\hline $66 a$ & 0 & 0 & 0 & 1 & 1 \\
\hline $66 b$ & 0 & 0 & 0 & 1 & 0 \\
\hline $72 a$ & 0 & 0 & 0 & 0 & 1 \\
\hline $72 b$ & 0 & 0 & 0 & 0 & 0 \\
\hline
\end{tabular}

\section{Conclusion}

Minimization of pocketing time by zigzag toolpath with passes selected along stability limit for optimality of radial and axial depth of cut pairs in VC is studied. The interest in zigzag toolpath stems from the fact that it maintains near to continuous tool-workiece contact as against the already studied one-way toolpath [77] with inherent delay stemming from return idle motions. The multimode (both up- and down-milling modes encountered) nature of zigzag toolpath together with the requirement that every pass must be optimized on a 
Chigbogu Ozoegwu, Sunday Ofochebe \& Chinedu Ezugwu, Int J Adv Manuf Technol The final publication is available at Springer via http://dx.doi.org/[DOI 10.1007/s00170-015-8108-9]

stability limit led to sixteen conditional expressions that constitute the functional space of zigzag pocketing time. The conditions act as the screening criteria that agree as to which of the expressions is effective given pocket size, tool size and tool regenerative dynamics. Comparison of zigzag and one-way toolpaths shows that the former always hastens pocketing operation because it better utilizes the stability limit of the system by maintaining continuously optimized to and fro passes. This is confirmed in numerical studies that give that zigzag toolpath can even half pocketing time of one-way toolpath for some choice of limiting process parameters. Similar to conclusion that has been drawn for one-way toolpath in an earlier work it is seen that utilizing the coordinate of maximum limiting material removal rate $\left(M R R_{\text {lim }}\right)$ for both down- and up-milling in a scheme of zigzag pocketing will not necessarily provide the minimum time because of geometrical constraints. It is seen that the two important factors that influence the relative performance of a regime of zigzag toolpath in terms of pocketing time is the number of the bivariately optimized passes between the first and last VCs and the average of $M R R_{\text {lim }}$ for such passes.

\section{References}

[1] Taylor F. W., On the art of cutting metals, Transactions of ASME, 28 (1907) 31-350.

[2] Tobias S., Fishwick W. (1958). The chatter of lathe tools under orthogonal cutting conditions. Transactions of the ASME, 80, 1079-1088.

[3] Tobias S., Fishwick W. (1958b) .Theory of regenerative machine tool chatter. The Engineer, 205, 199203.

[4] Tlusty, J., Polacek, J., and Polacek, M. (1963). The Stability of Machine Tools against Self Excited Vibrations in Machining. ASME International Research in Production Engineering, 1:465-474.

[5] Tobias, S.A. (1965). Machine Tool Vibration. Blackie and Sons Ltd.

[6] F. Koenigsberger, J. Tlusty, Machine Tool Structures, Stability against Chatter, Pergamon Press, 1967.

[7] Sridhar, R., Hohn, R.E., and Long, G.W. (1968). A Stability Algorithm for the General Milling Process. Trans. ASME Journal of Engineering for Industry, 90:330-334.

[8] Sridhar R, Hohn RE and Long GW, General Formulation of the Milling Process Equation, ASME J. of Eng. for Ind., 1968; 90: p.317-324.

[9] Opitz H., Bernardi, F. (1969). Investigation and calculation of the chatter behavior of lathes and milling machines. CIRP Annals-Manufacturing Technology, 18(2), 335-343.

[10] Minis I., Yanushevsky R., (1993). A new theoretical approach for the prediction of machine tool chatter in milling," Journal of Engineering for Industry, Vol.115, pp.1-8.

[11] Minis, I., Yanushevsky, T., Tembo, R., and Hocken, R. (1990). Analysis of Linear and Nonlinear Chatter in Milling. Annals of the CIRP, 39:459-462.

[12]Budak, E. (1994). The Mechanics and Dynamics of Milling Thin-Walled Structures. Ph.D. Dissertation, University of British Columbia.

[13] Altintas Y, Budak E, Analytical prediction of stability lobes in milling, CIRP Annals—Manufacturing Technology 44(1)(1995)357-362.

[14]Budak E., Altintas Y. (1998). Analytical prediction of chatter stability in milling-partI: General formulation. Transactions of the ASME, Journal of Dynamic Systems, Measurement, and Control, 120, 22-30.

[15] Budak E., Altintas Y. (1998). Analytical prediction of chatter stability in milling - part II: Application of the general formulation to common milling systems. Transactions of the ASME, Journal of Dynamic Systems, Measurement, and Control, 120, 31-36.

[16] Davies M., Dutterer J., Burns T. (2000). The stability of low radial immersion milling. CIRP AnnalsManufacturing Technology, 49(1), 37-40.

[17] Davies, M.A., Pratt, J.R., Dutterer, B., and Burns, T.J. (2002). Stability Prediction of Low Immersion Milling. Trans. ASME Journal of Manufacturing Science and Engineering, 124:217-225.

[18] Corpus, W.T. and Endres, W.J. (2004). Added Stability Lobes in Machining Processes That Exhibit Periodic Time Variation, Part 1: An Analytical Solution. Trans. ASME Journal of Manufacturing Science and Engineering, 126:467-474.

[19] Corpus, W.T. and Endres, W.J. (2004). Added Stability Lobes in Machining Processes That ExhibitPeriodic Time Variation, Part 2: Experimental Validation. Trans. ASME Journal of Manufacturing Science and Engineering, 126:475-480.

[20] S.D. Merdol, Y. Altintas, Multi frequency solution of chatter stability for low immersion milling, Journal of Manufacturing Science and Engineering 126 (2004) 459-467.

[21] Y. Altintas, M. Eynian, H. Onozuka, Identification of dynamic cutting force coefficients and chatter stability with process damping, CIRP Annals-Manufacturing Technology 57 (2008) 371-374.

[22] Y. Altintas, S. Engin, and E. Budak, "Analytical stability prediction and design of variable pitch cutters," Journal of Manufacturing Science and Engineering, vol. 121, no. 2, pp. 173-179, 1999. 
Chigbogu Ozoegwu, Sunday Ofochebe \& Chinedu Ezugwu, Int J Adv Manuf Technol The final publication is available at Springer via http://dx.doi.org/[DOI 10.1007/s00170-015-8108-9]

[23] Budak, E. (2003). An analytical design method for milling cutters with noncon-stant pitch to increase stability, parti: Theory. Transactions of the ASME, Journal of Manufacturing Science and Engineering, $125(1), 29-34$.

[24] Budak, E. (2003b). An analytical design method for milling cutters with noncon-stant pitch to increase stability, part2: Application. Transactions of the ASME, Journal of Manufacturing Science and Engineering, 125(1), 35-38.

[25] M. Zatarain, J. Munoa, G. Peigne' , T. Insperger, Analysis of the influence of mill helix angle on chatter stability, Annals of the CIRP 55 (2006) 365-368.

[26] Turner S., Merdol S., Altintas Y., Ridgway K. (2007). Modelling of the stability of variable helix endmills. International Journal of Machine Tools and Manufacture, 47 (9) 1410-1416.

[27] Merdol S., Altintas Y. (2004) Mechanics and dynamics of serrated cylindrical and tapered end-mills. Transactions of the ASME, Journal of Manufacturing Science and Engineering, 126 (2) 317-326.

[28] Sastry, S., Kapoor, S.G. and DeVor, R.E. (2002). Floquet theory based approach for stability analysis of the variable speed face-milling process. Transactions of the ASME, Journal of Manufacturing Science and Engineering, 124: 10-17.

[29]Zatarain, M., Bediaga, I., Muñoa, J. and Lizarralde, R. (2008). Stability of milling processes with continuous spindle speed variation: analysis in the frequency and time domains, and experimental correlation. Annals of the CIRP, 57, 379-384.

[30] Insperger T., Stability Analysis of Periodic Delay-Differential Equations Modelling Machine Tool Chatter: PhD dissertation, Budapest University of Technology and Economics (2002).

[31] Insperger T., Stepan G., Semi-discretization method for delayed systems, International Journal for Numerical Methods in Engineering 55(5) (2002) 503-518.

[32] Insperger T., Stepan G., Updated semi-discretization method for periodic delay differential with discrete delay. International Journal For Numerical Methods In Engineering 61(2004)117-141.

[33] Henninger C, Eberhard P, Improving the computational efficiency and accuracy of the semidiscretization method for periodic delay-differential equations, European Journal of Mechanics, A/Solids 27 (6) (2008) 975-985.

[34] Ahmadi, K., Ismail, F., 2012, Stability lobes in milling including process damping and utilizing multifrequency and semi-discretization methods, International Journal of Machine Tools and Manufacture, $54: 46-54$.

[35] K. Ahmadi, F. Ismail, Modeling chatter in peripheral milling using the Semi Discretization Method, CIRP Journal of Manufacturing Science and Technology 5 (2012) 77-86.

[36] Hamed Moradi, Gholamreza Vossoughi, Mohammad R. Movahhedy, Experimental dynamic modelling of peripheral milling with process damping, structural and cutting force nonlinearities, Journal of Sound and Vibration332(2013)4709-4731

[37] M. Wan, W.H. Zhang, J.W. Dang, Y Yang, A unified stability prediction method for milling process with multiple delays, International Journal of Machine Tools and Manufacture 50 (2010) 29-41.

[38] N.D. Sims, B. Mann, S. Huyanan, Analytical prediction of chatter stability for variable pitch and variable helix milling tools, Journal of Sound and Vibration 317 (2008) 664-686.

[39] Gang Jin, Qichang Zhang, Shuying Hao, Qizhi Xie (2013), Stability Prediction of Milling Process with Variable Pitch Cutter. Mathematical Problems in Engineering, Volume 2013, http://dx.doi.org/10.1155/2013/932013

[40] A. R. Yusoff and N. D. Sims, "Optimisation of variable helix tool geometry for regenerative chatter mitigation,” International Journal ofMachine Tools andManufacture, vol. 51,no. 2, pp. 133-141, 2011.

[41]Z.Dombovari andG. Stepan, "The effect of helix angle variation on milling stability," Journal of Manufacturing Science and Engineering, vol. 134, no. 5, 2012.

[42] S. Seguy, T. Insperger, L. Arnaud, G. Dessein, G. Peigne, On the stability of high-speed milling with spindle speed variation, International Journal of Advanced Manufacturing Technology 48 (2010) 883895.

[43] G. Totis, P. Albertelli, M. Sortino, M. Monno, Efficient evaluation of process stability in milling with Spindle Speed Variation by using the Chebyshev Collocation Method, Journal of Sound and Vibration, 333(2014)646-668.

[44]Zoltan Dombovari, Yusuf Altintas, Gabor Stepan. (2010) The effect of serration on mechanics and stability of milling cutters. International Journal of Machine Tools and Manufacture, 50 (6) 511-520

[45] T. Insperger, B.P. Mann, T. Surmann, G. Stepan, On the chatter frequencies of milling process with run-out, International Journal of Machine Tools and Manufacture 48 (2008) 1081-1089.

[46] Bayly P.V., Halley J.E., Mann B.P., Davies M.A., (2001) Stability of interrupted cutting by temporal finite element analysis, Proceedings of ASME Design Engineering Technical conference, DETC/2001 VIB-21581, Pittsburgh, PA. 
Chigbogu Ozoegwu, Sunday Ofochebe \& Chinedu Ezugwu, Int J Adv Manuf Technol The final publication is available at Springer via http://dx.doi.org/[DOI 10.1007/s00170-015-8108-9]

[47] Bayly PV, Schmitz T L, Stepan G, Mann B P, Peters D A, Insperger T. (2002) Effects of radial immersion and cutting direction on chatter instability in end-milling. Proceedings of IMECE'02 2002 ASME International Mechanical Engineering Conference \& Exhibition New Orleans, Louisiana, November 17-22, 2002.

[48] Insperger T, Mann BP, Stepan G, Bayly PV, Stability of up-milling and down-milling, part 1: alternative analytical methods, International Journal of Machine Tools \& Manufacture 43(2003) 2534.

[49] Bobrenkov O. A, Khasawneh F. A., Butcher E. A., Mann B. P., Analysis of milling dynamics for simultaneously engaged cutting teeth, Journal of Sound and Vibration 2010; 329: 585-606.

[50] Ozoegwu C. G., Omenyi S., Ofochebe S. M., Time Finite Element Chatter Stability Characterization of a Three Tooth Plastic End-Milling CNC Machine, American Journal of Computational and Applied Mathematics, 3(1)(2013) 1-7.

[51] Ozoegwu C. G, Omenyi S. N, Ofochebe S. M., Achebe C. H. Comparing up and Down Milling Modes of End-Milling Using Temporal Finite Element Analysis, Applied Mathematics 3(1) (2013) 1-11.

[52]B. R. Patel, B. P. Mann, and K. A. Young, "Uncharted islands of chatter instability in milling," International Journal of Machine Tools and Manufacture, vol. 48, no. 1, pp. 124-134, 2008.

[53] Ding Y, Zhu LM, Zhang XJ, Ding H. A full-discretization method for prediction of milling stability. International Journal of Machine Tools and Manufacture 50(2010) 502-509.

[54] Insperger T., Full-discretization and semi-discretization for milling stability prediction: Some comments. International Journal of Machine Tools and Manufacture 50(2010)658-662.

[55] Ding Y., Zhu L., Zhang X., Ding H., Second-order full-discretization method for milling stability prediction, International Journal of Machine Tools and Manufacture 50 (2010) 926-932.

[56] Y. Ding, L.M. Zhu, X.J. Zhang, H. Ding, Numerical integration method for prediction of milling stability, Journal of Manufacturing Science and Engineering 133 (2011) 031005-031009.

[57] Quo Q., Sun Y., Jiang Y., On the accurate calculation of milling stability limits using third-order fulldiscretization method, International Journal of Machine Tools \& Manufacture 62 (2012) 61-66.

[58] Yilong Liu, Dinghua Zhang, Baohai Wu, An efficient full-discretization method for prediction of milling stability, International Journal of Machine Tools \& Manufacture 63 (2012) 44-48.

[59] Ozoegwu, C. G., and Omenyi, S. N. (2013, July-August).Wave attenuation effects on the chatter instability of end-milling. Noise Control Engineering Journal, 61 (4) pp. 436-444.

[60] Ozoegwu C.G. (2014). Least squares approximated stability boundaries of milling process, International Journal of Machine Tools and Manufacture, 79, 24-30.

[61] Ozoegwu C.G., Omenyi S.N. and Ofochebe S.M. (2015). Hyper-third order full-discretization methods in milling stability prediction, International Journal of Machine Tools \& Manufacture 92 (2015) 1-9.

[62] Ozoegwu C. G. and Omenyi, S. N. (submitted in revised form). Third order least squares modelling of milling state term for improved computation of stability boundaries. Production \& Manufacturing Research.

[63] Y. Ding, L.M. Zhu, X.J. Zhang, H. Ding, Numerical integration method for prediction of milling stability, Journal of Manufacturing Science and Engineering 133 (2011) 031005-031009.

[64] Y. Ding, L. Zhu, X. Zhang, H. Ding, Milling stability analysis using the spectral method, Science China Technological Sciences54 (2011) 3130-3136.

[65] Xiao JianZhang, CaiHuaXiong, Ye Ding, Ming Jun Feng, You Lun Xiong, Milling stability analysis with simultaneously considering the structural mode coupling effect and regenerative effect, International Journal of Machine Tools \& Manufacture 53 (2012) 127-140

[66] Qizhi Xie, Qichang Zhang, Stability predictions of milling with variable spindle speed using an improved semi-discretization method, Mathematics and Computers in Simulation 85 (2012) 78-89

[67] Ozoegwu, C. G., Omenyi, S. N. and Ofochebe S. M. (2015). Curvature Effects on Circular Feed EndMilling, Part 1: Modelling and Simulation. International Journal of Engineering Systems Modelling and Simulation 7(3) pp.147-157.

[68] Ozoegwu CG, Omenyi SN (2015) Curvature effects on circular feed end-milling, part 2: stability analysis. Int J Eng Syst Model Simul 8(1):20-27.

[69] Eric A. Butcher, Oleg A. Bobrenkov, Ed Bueler, Praveen Nindujarla (2009) Analysis of Milling Stability by the Chebyshev Collocation Method: Algorithm and Optimal Stable Immersion Levels. Journal of Computational and Nonlinear Dynamics. JULY 2009, Vol. 4 / 031003-1

[70] S. Yi, P. Nelson, A. Ulsoy, Delay differential equations via the matrix Lambert W function and bifurcation analysis: application to machine tool chatter, Mathematical Biosciences and Engineering 4(2) (2007)355-368.

[71] Tao Huang, Xiaoming Zhang, Xiaojian Zhang, Han Ding, An efficient linear approximation of acceleration method for milling stability prediction, International Journal of Machine Tools \& Manufacture 74(2013)56-64. 
Chigbogu Ozoegwu, Sunday Ofochebe \& Chinedu Ezugwu, Int J Adv Manuf Technol The final publication is available at Springer via http://dx.doi.org/[DOI 10.1007/s00170-015-8108-9]

[72] M. Li, G. Zhang, Y. Huang, Complete discretization scheme for milling stability prediction, Nonlinear Dynamics 71 (2012) 187-199.

[73] Merdol, S. Doruk, Altintas, Yusuf, 2008, Virtual cutting and optimization of three-axis milling processes, International Journal of Machine Tools and Manufacture, 48/10: 1063-1071.

[74] Eun Young Heo, Doruk Merdol, Yusuf Altintas (2010) High speed pocketing strategy. CIRP Journal of Manufacturing Science and Technology 3 (2010) 1-7

[75] A. Tekeli and E. Budak, (2005) Maximization of chatter-free material removal rate in end milling using analytical methods, Machining Science and Technology, 9:147-167

[76] Budak, E., Tekeli, A., (2005) Maximizing chatter-free material removal rate in milling through optimal selection of axial and radial depth of cut pairs, CIRP Annals - Manufacturing Technology, 54/1: 353356.

[77] Ozoegwu C.G., Ezugwu C. (2015). Minimizing pocketing time by selecting most optimized chronology of tool passes. International journal of advanced manufacturing technology, 81:16671682. DOI 10.1007/s00170-015-6943-3.

[78] Weck, M., Altintas, Y., and Beer, C. (1994). CAD Assisted Chatter Free NC Tool Path Generation in Milling. International Journal of Machine Tools and Manufacture, 34:879-891 
Chigbogu Ozoegwu, Sunday Ofochebe \& Chinedu Ezugwu, Int J Adv Manuf Technol The final publication is available at Springer via http://dx.doi.org/[DOI 10.1007/s00170-015-8108-9]

Appendix

A flowchart of stability computation on the plane axial depth and radial immersion

Table 2 Parameters

$\begin{array}{llllll}\Omega & r & l & n & w_{1} & w_{n+1}\end{array}$

$\rho_{1} \rho_{n+1}$

$\Delta w=\left(w_{l+1}-w_{1}\right) / l$

$\Delta \rho=\left(\rho_{l+1}-\rho_{1}\right) / n$

$\tau=60 /(N \Omega) \quad \Delta t=\tau / r$

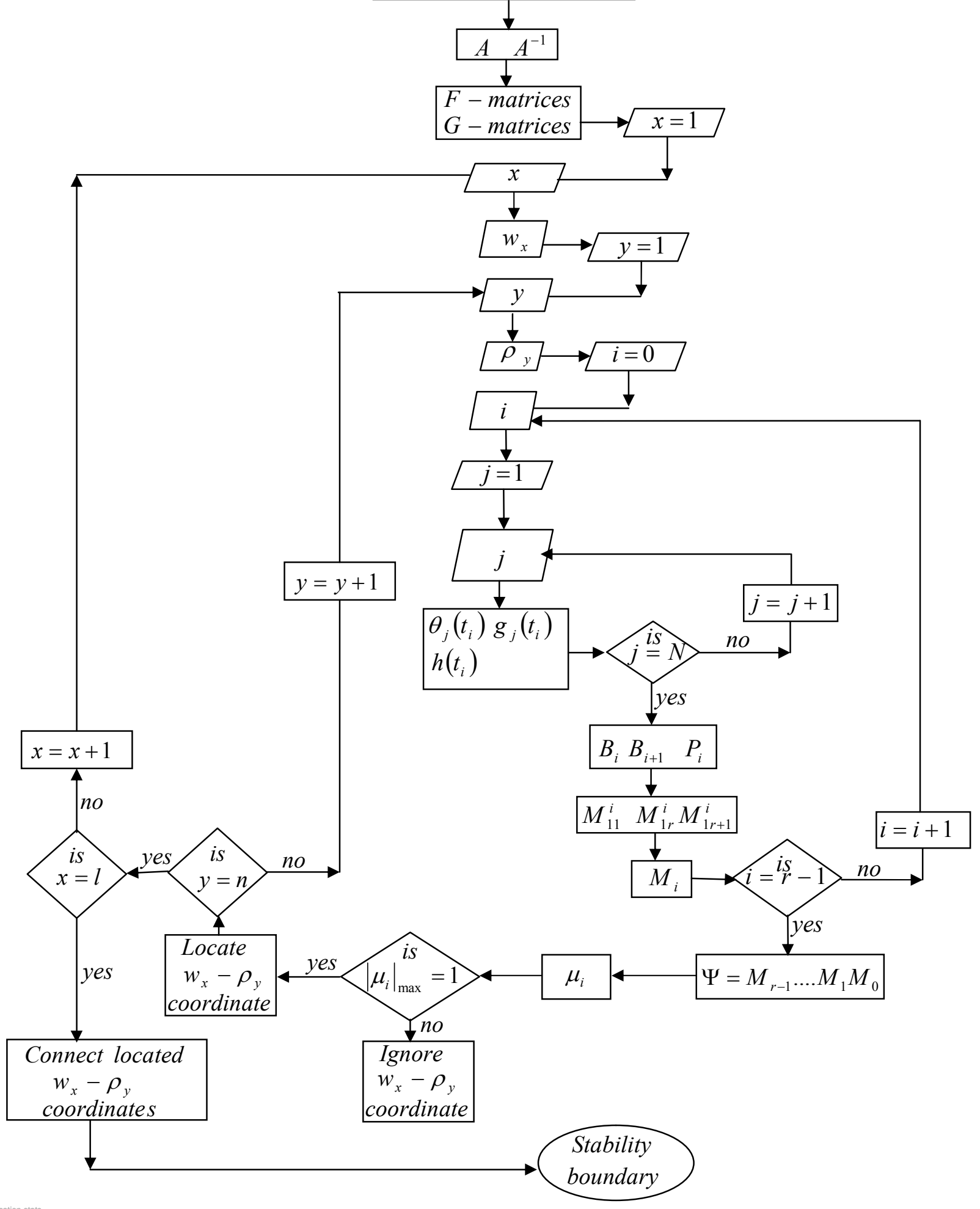

